\title{
ANÁLISIS DE LA ECONOMÍA COLABORATIVA EN EL TURISMO URBANO. ESTUDIO DE LA IMPLANTACIÓN DE AIRBNB EN MADRID Y BARCELONA $^{1}$
}

\author{
Elena Cerdá Mansilla* \\ Universidad Autónoma de Madrid \\ https://orcid.org/0000-0002-8518-7120 \\ Blanca García Henche ${ }^{* *}$ \\ Universidad de Alcalá \\ https://orcid.org/0000-0002-9824-7372 \\ María Jesús Such Devesa*** \\ Universidad de Alcalá \\ https://orcid.org/0000-0001-9469-3730
}

\section{RESUMEN}

El presente artículo pretende contribuir a la investigación de los modelos de gestión urbana considerando la economía colaborativa, añadiendo una perspectiva integradora que evalúa el impacto real en el territorio de los alojamientos reglados y no reglados en las ciudades, con el fin de garantizar la sostenibilidad de los destinos a largo plazo, la experiencia del turista y la calidad de vida de los residentes.

Se analizan los datos de los hoteles y los apartamentos turísticos junto con los de Airbnb y se cartografía la distribución de los nuevos indicadores capaces de reflejar la situación real que están experimentado la demanda y la oferta alojativa en Madrid y Barcelona.

Fecha de recepción: 16 de diciembre de 2019.

Fecha de aceptación: 8 de junio de 2020.

1 El presente trabajo se ha desarrollado gracias a la obtención de Ayuda para el Fomento de la Investigación en Máster de la Universidad Autónoma de Madrid, así como mediante el posterior contrato predoctoral de Formación de Personal Investigador (FPI-UAM) en la Universidad Autónoma de Madrid.

* Departamento de Financiación e Investigación Comercial, Facultad de Ciencias Económicas y Empresariales. Universidad Autónoma de Madrid, Ctra. Colmenar, C/ Francisco Tomás y Valiente, $\mathrm{n}^{\circ}$ 5, 28049 MADRID (España) 28049. E-mail: elena.cerda@uam.es.

** Departamento de Economía y Dirección de Empresas. Facultad de Ciencias Económicas y Turismo. Universidad de Alcalá. Plaza de la Victoria s/n. 28802 ALCALÁ DE HENARES. Madrid (España). E-mail: blanca.garcia@uah.es.

***Departamento de Economía. Facultad de Ciencias Económicas y Turismo. Universidad de Alcalá. Plaza de la Victoria, s/n. 28802 ALCALÁ DE HENARES. Madrid (España). E-mail: mjesus.such@uah.es. 
Gracias a esos indicadores se podrá aproximar una medición real de la economía colaborativa para garantizar la sostenibilidad de los destinos turísticos.

Palabras clave: Airbnb; economía colaborativa; alojamiento turístico; sostenibilidad; destino turístico inteligente y colaborativo.

\title{
Analysis of the sharing economy in urban tourism. Study of the implementation of Airbnb in Madrid and Barcelona
}

\begin{abstract}
This paper seeks to contribute to the investigation of urban management models considering the sharing economy. Adding an integrative perspective that evaluates the real impact on the territory of regulated and unregulated accommodation in cities in order to guarantee the sustainability of the long-term destinations, the tourist experience and the quality of life of the residents.

The data of the hotels and tourist apartments are analyzed together with those of Airbnb. The data of the distribution of holiday dwellings offered by Airbnb were mapped out as new indicators capable of reflecting the real situation that demand and housing supply are experiencing in Madrid and Barcelona.

It is understood that thanks to these indicators, tourist destinations are able to direct exchanges between collaborative economy and smart economy toward achieving the purpose of the model: making destinations sustainable.
\end{abstract}

Keywords: Airbnb; share economy; tourist accommodation; sustainability; smart and sharing destination.

\section{INTRODUCCIÓN}

En un contexto económico marcado por una profunda crisis internacional los hábitos de los consumidores y el modo por el cual tratan de satisfacer sus necesidades están cambiando. Existen muchos escenarios en los que ya no es necesario adquirir la propiedad del bien, siendo suficiente con disponer de la posibilidad de acceder al mismo, es decir, se cambia el "poseer" por el "compartir". En el sector turístico esta tendencia cobra cada vez más fuerza.

Así, el presente trabajo surge motivado por el contexto actual en el que se encuentra el sector turístico, donde se están produciendo cambios continuos que están provocando la aparición de modelos de gestión de oferta y demanda turística totalmente disruptivos.

Desde los años 60, y hasta hoy en día, la evolución del sector turístico ha sido considerable y su función en la transformación de las ciudades es cada vez más marcada. Ello obliga a que los destinos y los agentes implicados en el sector turístico sean capaces de reinventarse.

En esa reinvención aparecen los conceptos marketing urbano y city marketing, como formas de impulsar la ciudad hacia el exterior. Si bien, se ha de entender que el marketing urbano se refiere a la ciudad en su conjunto y el city marketing pone su foco de atención en el centro de la ciudad, su comercio, su cultura y sus residentes. 
Por otra parte, el consumidor turístico actual busca ser protagonista de su propia experiencia (Rivera, 2013 y Sainz, 2015). Los turistas empiezan a mostrar interés por el patrimonio cultural y por el consumo activo de cultura en unas ciudades renovadas y dispuestas a satisfacer esas necesidades. Así, el nuevo tipo de turista, no se conforma con los modelos turísticos tradicionales y busca nuevas experiencias, busca emocionarse y vivir la ciudad disfrutando de ella como un todo (G. Henche y Salvaj, 2017). Se trata, por tanto, del consumo de una ciudad diseñada en base a todas las características y elementos que la componen, desde sus barrios, sus monumentos, comercios, hostelería y otras formas de alojamiento, hasta las costumbres locales, la cultura y la gente.

Es principalmente por la importancia del sector turístico en España, que cabe detenerse a analizar uno de los focos principales de este proyecto relacionado con el turismo urbano y el city marketing: la economía colaborativa. Esta surge apoyada por la transformación digital y determina una modificación de la estructura de la oferta y demanda turística.

El nuevo panorama del sector turístico hace necesario analizar la necesidad de regulación, ya que su ausencia desencadena fallos irreversibles que no permiten en la economía colaborativa cumpla con su fin social.

Al realizar una aproximación a del fenómeno turístico en España, se puede afirmar que España es uno de los líderes mundiales indiscutibles del sector turístico, donde dicho sector supone un 14,6\% del PIB en 2018. En cuanto, a las llegadas de turistas internacionales, España recibió en 2018 más de 82,6 millones de turistas, siendo la segunda potencia mundial después de Francia, y la segunda en gasto efectuado por los turistas con cerca de 90.000 millones de euros, detrás sólo de EE.UU (INE, 2018).

Según el World Travel Monitor de ITB, los viajes de los turistas europeos a países extranjeros aumentaron un 2,5\% en 2016 de media y el segmento que más creció fue el turismo urbano, con un aumento del $15 \%$. Uno de los destinos más favorecidos por esta tendencia es España. Así, el aumento del turismo en las ciudades españolas durante los nueve primeros meses de 2016 fue del 14\%, frente al del 0,4\% del crecimiento medio europeo (European Cities Marketing, 2016).

En este contexto, la presente investigación propone como objetivo principal analizar la situación de la economía colaborativa en el sector del alojamiento, para poder ofrecer un conjunto de datos que nos pueda encaminar a la obtención de una visión global de la situación del sector turístico, mediante el estudio de las ciudades de Madrid y Barcelona.

La razón de la elección de dichas ciudades, en el caso de España, es que ambas son líderes europeos a nivel turístico, según el informe sobre el Índice Global de Ciudades Destino, ambas ciudades se encuentran entre las diez primeras de Europa en recepción de turistas (Barcelona en tercer lugar y Madrid en cuarto) y entre las veinte primeras del mundo en cuanto al gasto por pernoctaciones de visitantes internacionales a nivel mundial (Barcelona en décimo lugar y Madrid en duodécimo), según Mastercard (2017).

El artículo se organiza de la siguiente manera: en primer lugar, se revisa la literatura sobre las características de la economía colaborativa en el sector turístico. En segundo lugar, se analizan los motivos por los que Madrid y Barcelona son referentes internacionales de turismo urbano y, seguidamente se describe la oferta alojativa reglada de ambas ciudades. Posteriormente se realiza un análisis del impacto de Airbnb en Madrid y Barce- 
lona en términos de número de apartamentos, densidad de plazas turísticas por kilómetro cuadrado y precios (distribuidos por distritos).

A continuación, se desarrolla la metodología de la investigación y seguidamente, se presentan los resultados del estudio. Finalmente, se elaboran las conclusiones del estudio realizado.

La metodología de la investigación se basa en los estudios de caso de Madrid y Barcelona. Se realiza un análisis descriptivo de la demanda y de la oferta turística a través de variables extraídas del Instituto Nacional de Estadística.

El estudio llevado a cabo realiza una aportación complementaria desde dos tipos de alojamiento, los hoteles y los apartamentos turísticos, con el fin de conciliar de manera realista la situación actual de ambos. Además, se realizará una aportación externa al INE, extrayendo de la base de datos del investigador Tom Slee: el número de alojamientos de Airbnb, su localización y su precio (tanto de Madrid como de Barcelona)con el fin de cuantificar la situación real de los apartamentos turísticos en ambas ciudades.

\section{MARCO TEÓRICO: CARACTERÍSTICAS DE LA ECONOMÍA COLABORA- TIVA EN EL SECTOR TURÍSTICO}

El término economía colaborativa nace del concepto consumo colaborativo, que surge en 1978, cuando Marcus Felson y Joe L. Spaeth publicaron su libro "Community Structure and Collaborative Consumption: A routine activity approach", mediante el cual comenzaron su discusión acerca de los bienes compartidos con otros consumidores (Felson y Spaeth 1978, pp. 614-624).

Por su parte, Ray Algar aportó con su artículo "Collaborative Consumption" la definición de consumo colaborativo como un movimiento en el que los usuarios colaboran en línea para intercambiar bienes y servicios, compartir experiencias y unir su poder adquisitivo colectivo para co-poseer activos de alto valor, a través de plataformas (Algar, 2007).

Sin embargo, el concepto "economía colaborativa", comienza a hacerse popular con la publicación de "What's Mine Is Yours: The Rise of Collaborative Consumption" de Rachel Botsman y Roo Rogers.

Rachel Botsman trató de asentar la concepción del nuevo término, economía colaborativa, haciéndolo ver como una posibilidad de cambio motivada por una crisis financiera internacional, en la cual los individuos, reconociendo su sentimiento de comunidad, comprometidos con el medioambiente y adversos al consumo desaforado, se transforman en sujetos creadores que intervienen en un mercado, en el cual su moneda de cambio es la confianza.

El término originariamente empleado para describir el fenómeno fue el de "consumo colaborativo" (collaborative consumption), pero resultó insuficiente por ser la economía colaborativa algo más que consumo. También es frecuente el término "economía entre pares" (peer-P2P-economy), que se aplica a organizaciones surgidas en torno al modelo de negocio peer-to-peer, en el que las plataformas se usan para alquilar, vender, prestar o compartir bienes al margen de tiendas, bancos o agencias; pero tampoco esta realidad engloba toda la economía colaborativa pues deja fuera otras fórmulas entre empresarios y consumidores, empresarios y empresarios o, incluso, entre consumidores y empresarios permitiendo que esté al alcance de cualquiera y modificado la oferta turística, incorporando a nuevos agentes que 
ya no solo demandan sino que también ofertan y donde los consumidores se convierten en proveedores. Esta transformación trae un nuevo modelo conocido como P2P (Alfonso, 2016).

La Comisión Nacional de los Mercados y la Competencia (2016, p.17) define la economía colaborativa como "un conjunto heterogéneo y rápidamente cambiante de modos de producción y consumo por el que los agentes comparten, innovadoramente, activos, bienes o servicios infrautilizados, a cambio o no de un valor monetario, valiéndose para ello de plataformas digitales y, en particular, de Internet", definición que añade la necesidad de la economía colaborativa de valerse de las herramientas digitales.

Ante las múltiples definiciones de diferentes autores, se puede tratar de sintetizar los elementos clave comunes en las definiciones de economía colaborativa, como son: a) la capacidad de facilitar el intercambio entre extraños más que entre parientes o dentro de la comunidad; b) la fuerte dependencia de la tecnología que también puede favorecer las actividades offline; y c) la participación de consumidores de alto capital cultural en vez de limitarse a mecanismos de supervivencia entre los más desfavorecidos (Codagnone y Martens, 2016).

La tabla 1 recoge un esquema de los distintos autores que han tratado el término "economía colaborativa" y las definiciones del mismo.

\section{Tabla 1 \\ EVOLUCIÓN DE LAS ACEPCIONES DE LA ECONOMÍA COLABORATIVA}

\begin{tabular}{|c|c|c|c|}
\hline Año & Autores & Nombre & Definición/Teoría \\
\hline 1978 & Felson y Spaeth & $\begin{array}{l}\text { Collaborative } \\
\text { Consumption }\end{array}$ & Bienes compartidos con otros consumidores. \\
\hline 2007 & Algar & $\begin{array}{l}\text { Collaborative } \\
\text { Consumption }\end{array}$ & $\begin{array}{l}\text { Movimiento en el que los usuarios colaboran } \\
\text { en línea para intercambiar bienes y servicios, } \\
\text { compartir experiencias y unir su poder adquisitivo } \\
\text { colectivo paraco-poseer activos de alto valor; a } \\
\text { través de plataformas. }\end{array}$ \\
\hline 2010 & Botsmany Rogers & $\begin{array}{l}\text { Collaborative } \\
\text { Consumption }\end{array}$ & $\begin{array}{l}\text { Cambio motivado por una crisis financiera } \\
\text { internacional, en la que los individuos, se } \\
\text { transforman en sujetos } \\
\text { creadores interviniendo en un mercado, cuya } \\
\text { moneda de cambio es la confianza. }\end{array}$ \\
\hline 2010 & Gansky & $\begin{array}{l}\text { "the mesh" } \\
\text { Share economy }\end{array}$ & $\begin{array}{l}\text { Modelo de consumo que consiste en préstamos, } \\
\text { intercambios, contratos de trueque o acceso } \\
\text { pagado a bienes en lugar de la posesión de los } \\
\text { mismos. }\end{array}$ \\
\hline 2012 & Bardhiy Eckhardt & $\begin{array}{l}\text { Access-based } \\
\text { consumption }\end{array}$ & $\begin{array}{l}\text { Transacciones que pueden ser mediadas por el } \\
\text { mercado } \\
\text { pero en las que no se produce transferencia de } \\
\text { propiedad y difieren tanto de la propiedad como } \\
\text { del intercambio }\end{array}$ \\
\hline
\end{tabular}




\begin{tabular}{|c|c|c|c|}
\hline Año & Autores & Nombre & Definición/Teoría \\
\hline 2013 & Opciones & $\begin{array}{l}\text { Economía } \\
\text { colaborativa }\end{array}$ & $\begin{array}{l}\text { Movimiento que engloba nuevas prácticas } \\
\text { económicas que tienen en común algún grado } \\
\text { de participación u colectiva en la provisión de } \\
\text { bienes/servicios. }\end{array}$ \\
\hline 2014 & $\begin{array}{l}\text { Vaughan y } \\
\text { Hawksworth }\end{array}$ & $\begin{array}{l}\text { Sharing } \\
\text { economy }\end{array}$ & $\begin{array}{l}\text { Uso plataformas digitales para permitir que los } \\
\text { clientes } \\
\text { tengan acceso a activos tangibles e intangibles, en } \\
\text { lugar de ser sus propietarios. }\end{array}$ \\
\hline 2014 & $\begin{array}{l}\text { Comisión Nacional } \\
\text { de los Mercados y } \\
\text { la Competencia }\end{array}$ & $\begin{array}{l}\text { Economía } \\
\text { colaborativa }\end{array}$ & $\begin{array}{l}\text { Modelo de consumo basado en el intercambio } \\
\text { entre particulares de bienes y servicios que } \\
\text { permanecían ociosos o infrautilizados a cambio de } \\
\text { una compensación } \\
\text { pactada entre las partes. }\end{array}$ \\
\hline 2014 & Cañigueral & $\begin{array}{l}\text { Economía } \\
\text { colaborativa }\end{array}$ & $\begin{array}{l}\text { Herramienta de mercado complementaria capaz } \\
\text { de regenerar la economía y dirigirla hacia una } \\
\text { economía sostenible. }\end{array}$ \\
\hline 2014 & Belk & $\begin{array}{l}\text { Collaborative } \\
\text { consumption }\end{array}$ & $\begin{array}{l}\text { Personas que coordinan la adquisición y } \\
\text { distribución de un recurso por una tarifa u otra } \\
\text { compensación. }\end{array}$ \\
\hline $\begin{array}{l}2014 \\
-2015\end{array}$ & $\begin{array}{l}\text { Dubois et al.; Schor } \\
\text { y Fitzmaurice }\end{array}$ & $\begin{array}{l}\text { Connected } \\
\text { consumption }\end{array}$ & Actividades económicas conectadas digitalmente. \\
\hline 2015 & Hamari et al., & $\begin{array}{l}\text { Collaborative } \\
\text { consumption }\end{array}$ & $\begin{array}{l}\text { Una actividad entre pares para obtener, dar o } \\
\text { compartir } \\
\text { el acceso a bienes y servicios, que se coordina } \\
\text { a través una comunidad basada en los servicios } \\
\text { on-line. }\end{array}$ \\
\hline 2016 & $\begin{array}{l}\text { Comisión Nacional } \\
\text { de los Mercados y } \\
\text { la Competencia }\end{array}$ & $\begin{array}{l}\text { Economía } \\
\text { colaborativa }\end{array}$ & $\begin{array}{l}\text { Un conjunto heterogéneo y cambiante de modos } \\
\text { de producción y consumo por el que los agentes } \\
\text { comparten, innovadoramente, activos, bienes o } \\
\text { servicios, a cambio o no de un valor monetario, } \\
\text { valiéndose para ello de internet. }\end{array}$ \\
\hline 2016 & Ouishare & $\begin{array}{l}\text { Economía } \\
\text { colaborativa }\end{array}$ & $\begin{array}{l}\text { Modelo basado en eliminar las limitaciones } \\
\text { existentes entre el productor y el consumidor y } \\
\text { facilitando la interactuación mediante internet } \\
\text { y plataformas peer-to- peer (P2P), así como } \\
\text { valorando otras experiencias offline. }\end{array}$ \\
\hline
\end{tabular}

Fuente: Elaboración propia.

Independientemente de la definición tratada, es evidente que el surgimiento de los sistemas de economía colaborativa está revolucionando la realización de múltiples actividades de producción y consumo de bienes y servicio (Doménech, 2015). 
Por otra parte, se ha de reconocer la aportación de Albert Cañigueral (2014), puesto que representa una de las aportaciones más enriquecedoras desde España en cuanto a economía colaborativa. En su libro "Vivir con menos", plantea la economía colaborativa como una herramienta de mercado complementaria capaz de regenerar la economía y dirigirla hacia una economía sostenible.

Cabe destacar que, en España, este término comenzó a utilizarse entre el 2012 y 2013, y que su uso destacó, especialmente, en el sector turístico. Por ello, el motivo que justifica el interés del presente estudio viene dado por el impacto en el sector turístico.

Un primer paso para poder analizar la economía colaborativa en el sector turístico es evaluar la repercusión de la economía colaborativa directamente en este sector.

Aunque la economía colaborativa se está aplicando a múltiples sectores económicos claves, el sector turismo está siendo el más afectado por la economía colaborativa, principalmente en aspectos relacionados con las decisiones sobre elección del destino de viaje (Tussyadiah y Pesonen, 2015), el incremento en la frecuencia de los viajes, la duración de las estancias y el tipo de productos y servicios consumidos durante el viaje (Tussyadiah y Pesonen, 2016, Leal y Medina, 2018).

A pesar de que el sector turismo está configurado por un amplio espectro de actividades ofrecidas por empresas e instituciones muy variadas e interconectadas, sin duda los dos ámbitos en los que mayor peso está teniendo la economía colaborativa son el transporte y el alojamiento (Alonso et al.2018 y Rodríguez-Antón et al., 2016). Así, se han generalizado de forma extraordinaria diferentes alternativas al alojamiento vacacional más tradicional, mediante plataformas virtuales que ofrecen viviendas privadas para su uso turístico a precios competitivos y prometen experiencias más cercanas a la convivencia vecinal que turística (De la Encarnación, 2015 y Moreno et al., 2016)

Previamente a analizar las características específicas en el sector turístico, se debe estudiar la evolución de este tipo de economía potenciada por el uso de la tecnología, para poder convertirse en un negocio. Por ello, se revisa el Estudio de Consumo Colaborativo: ¿Colaboración o negocio? realizado por la OCU en 2016, que organiza a las plataformas dentro de 3 grandes grupos en función de su propósito:

- Un $46 \%$ de las plataformas (55\% de las 21 que operan en España) se orientan a la conexión de redes de usuarios que se basan en intereses comunes y en reputación virtual. Destacando entre ellas, Airbnb como ejemplo de alojamiento colaborativo y Blablacar como ejemplo de servicios de coche compartido.

- Un $28 \%$ de las plataformas (35\% de las españolasa) se orientan a la transacción, es decir su finalidad es facilitar intercambios prácticos entre sus usuarios. Houseaway como ejemplo de alojamiento colaborativo y Amovens como ejemplo de servicios de coche compartido.

- Un $26 \%$ de las plataformas (10\% de las españolas) se orientan a la comunidad y se plantean mejoras sociales, así como fomentar hábitos de consumo sostenibles.

En el presente trabajo, tan solo se analizan las plataformas del primer grupo, por lo que se podría considerar que la mayoría de estas plataformas no se sustentan de comunidades sino de networks (redes), entendiéndolos como redes de individuos que se interrelacionan, comparten y producen alianzas en función de intereses concretos. 
Por otra parte, ante estos gigantes de la economía colaborativa como Airbnb, han surgido las denominadas plataformas cooperativas, las cuales se sustentan en la ética y la sostenibilidad (Scholz, 2014). En éstas, el interés son las comunidades, reconociéndolas como el máximo grado de empoderamiento de las personas. Un claro ejemplo de plataforma cooperativa es Fairbnb, que surge como una solución frente a la gentrificación de Airbnb, convirtiéndose en una plataforma de propiedad colectiva gestionada de manera conjunta por quienes sufren el impacto de la actividad turística y cuyos beneficios serán reinvertidos en proyectos sociales para los propios barrios.

\section{MADRID Y BARCELONA COMO REFERENTES TURÍSTICOS INTERNA- CIONALES}

Tanto Madrid como Barcelona, tienen una imagen reconocida como destinos turísticos inteligentes (Buhalis y Amaranganna 2013; Koo et al., 2016; Muñoz y Sánchez, 2013; López de Ávila y García, 2015; Fernández et al., 2017). Además, reciben una gran parte de los turistas que llegan a España (según la encuesta de ocupación hotelera 12.066.592 y 12.066.363 turistas visitaron y se alojaron en 2017 en establecimientos hoteleros en Madrid y Barcelona, respectivamente). Además, entre las dos ciudades poseen casi un $20 \%$ del total nacional de plazas hoteleras y un $12 \%$ del total nacional de plazas de apartamentos (INE, 2017).

En el informe sobre el Índice Global de Ciudades Destino (Mastercard, 2017), ambas ciudades se encuentran entre el top 10 europeo (Barcelona en tercer lugar y Madrid en cuarto) y top 20 mundial (Barcelona en décimo lugar y Madrid en duodécimo) en cuanto al gasto por pernoctaciones de visitantes internacionales a nivel mundial (Véase tabla 2). Los visitantes internacionales se dejaron durante el 2016 en Barcelona alrededor de 8.904 millones de dólares (7.552 millones de euros) y en Madrid la cifra fue de 7.666 millones (6.500 millones de euros). Este es uno de los hechos que acredita a ambas ciudades de un notable potencial turístico mundial.

Tabla 2

\section{CLASIFICACIÓN DE BARCELONA Y MADRID EN EL RANKING MUNDIAL DE LAS 20 CIUDADES CON MAYOR GASTO POR PERNOCTACIONES DE VISITANTES INTERNACIONALES EN 2016}

\begin{tabular}{|l|c|c|c|c|c|c|c|c|}
\hline & & \multicolumn{6}{|c|}{$\begin{array}{l}\text { 2016 Gastode visitantes internacionales por } \\
\text { pernoctación (mil millones de dólares) }\end{array}$} & \\
\hline \multicolumn{1}{|c|}{ Ciudad destino } & País & 2012 & 2013 & 2014 & 2015 & 2016 & $\begin{array}{c}2017 \\
\text { (predicc) }\end{array}$ & $\begin{array}{c}2016 \\
\text { Visitantes }\end{array}$ \\
\hline 10. Barcelona & España & $\$ 7,61$ & $\$ 8,65$ & $\$ 8,87$ & $\$ 7,73$ & $\$ 8,90$ & $6,9 \%$ & 8,4 Millones \\
\hline 12. Madrid & España & $\$ 6,06$ & $\$ 6,40$ & $\$ 7,15$ & $\$ 6,79$ & $\$ 7,67$ & $5,5 \%$ & 5,2 Millones \\
\hline
\end{tabular}

Fuente: Elaboración propia a partir del Índice Global de Ciudades Destino de MasterCard 2017. 
El mismo informe (Mastercard, 2017), recoge una clasificación de países por millones de visitantes, tal como se observa en la tabla 3. En este caso, Barcelona se mantiene en la clasificación mundial, en el mismo lugar del año 2016: el duodécimo. Pero Madrid, pierde tres posiciones y ocupa el vigésimo quinto puesto en la clasificación, por lo que no entra a estar considerada dentro del top 20 mundial ni en el top 10 europeo en cuanto a número de visitantes internacionales (en el caso europeo, Barcelona ocupaba la cuarta posición y Madrid la duodécima). Así, Barcelona consiguió atraer a 8,36 millones de visitantes extranjeros en 2016, mientras que Madrid, recibió 5,23 millones de visitas extranjeras en 2016.

Tabla 3

\section{CLASIFICACIÓN DE BARCELONA Y MADRID EN EL RANKING GLOBAL DE LAS 25 CIUDADES CON MÁS VISITANTES INTERNACIONALES} (2016-2017).

\begin{tabular}{|l|l|l|l|l|l|}
\hline $\begin{array}{c}\text { Ranking 2017 } \\
(\mathbf{2 0 1 6})\end{array}$ & \multicolumn{1}{|c|}{ Ciudad } & $\begin{array}{c}\text { Visitantes } \\
\mathbf{2 0 1 6} \\
\text { (Millones.) }\end{array}$ & $\begin{array}{c}\text { Previsión } \\
\mathbf{2 0 1 7}\end{array}$ & $\begin{array}{c}\text { Gasto } \\
\text { Visitantes } \\
\mathbf{2 0 1 6}\end{array}$ & $\begin{array}{c}\text { Previsión de } \\
\text { crecimiento } \\
\mathbf{2 0 1 7}\end{array}$ \\
\hline $\mathbf{1 2}(\mathbf{1 2})$ & Barcelona & 8,36 & $6,5 \%$ & $\begin{array}{l}\text { 8.904 Millones } \\
\text { de Dólares }\end{array}$ & $6,9 \%$ \\
\hline $\mathbf{2 5}(\mathbf{2 2})$ & Madrid & 5,23 & $5,2 \%$ & $\begin{array}{l}\text { 7.666 Millones } \\
\text { de Dólares }\end{array}$ & $5,5 \%$ \\
\hline
\end{tabular}

Fuente: Clasificación del Índice Global de Ciudades Destino de Mastercard del 2017.

\section{LA PERSPECTIVA ALOJATIVA REGLADA. ANÁLISIS DE MADRID Y BAR- CELONA}

\subsection{Comparativa del sector hotelero y del sector de los apartamentos turísticos reglados entre Madrid y Barcelona}

Tanto Madrid como Barcelona tienen una amplia oferta alojativa, diferenciándose en que Barcelona posee en 2018 más establecimientos hoteleros abiertos que Madrid (1.135 frente a los 1.085 de Madrid), mientras que Madrid posee un número mayor de apartamentos turísticos (3.751 frente a 2.880 de Barcelona), según el INE, 2018.

Desde el punto de vista hotelero (ver figura 1) el porcentaje de viajeros que reciben Madrid y Barcelona es claramente representativo al considerarse en el estudio un total de 52 ciudades españolas. Madrid tiene una mayor tendencia a acoger turistas residentes que Barcelona (12,4\% frente a 6,7\%), si bien Barcelona, acoge una mayor proporción de turistas no residentes (16,3\% frente a un 10,7\%) del 100\% de visitantes que recibe España.

En cuanto a las pernoctaciones, ambas ciudades también tienen una alta representatividad a nivel nacional. Aunque, Madrid es menos significativa en cuanto al total de viajeros y a los no residentes, sin embargo, en el caso de los residentes es más representativa que Barcelona. Por otra parte, según el grado de ocupación medio de los hoteles por habitaciones en 2017, ambas ciudades superan la media nacional (67,2\% es el grado de ocupación medio nacional frente al 72,4\% de Madrid y el 69,1\% de Cataluña). 
Desde el punto de vista de los apartamentos turísticos (ver figura 2), el porcentaje de viajeros, tanto totales, como residentes y no residentes de ambas ciudades sobre el total nacional, sigue siendo representativo, aunque no tanto como lo era en el caso de los hoteles y, se consideran en el estudio la aportación de tan sólo 19 territorios nacionales.

En el caso de las pernoctaciones en apartamentos la Comunidad de Madrid, con un $2 \%$ del total, es menos representativa que Cataluña (teniendo cuenta que la valoración se realiza por Comunidad Autónoma, pero dentro de ésta, Barcelona tiene un elevado peso relativo), con un 9\% del total de pernoctaciones realizadas en 2017 en toda España.

\section{Figura 1}

\section{PORCENTAJE DE VIAJEROS QUE VISITARON ESPAÑA Y SE ALOJARON EN HOTELES DE MADRID O BARCELONA EN 2017}

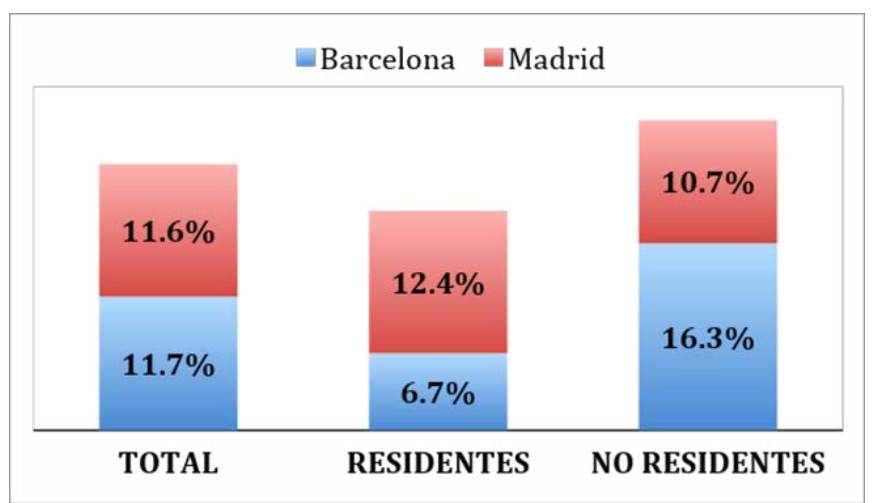

Fuente: Elaboración propia a partir la Encuesta de Ocupación Hotelera Española del INE, 2018.

Figura 2

PORCENTAJE DE VIAJEROS QUE VISITARON ESPAÑA Y SE ALOJARON EN APARTAMENTOS TURÍSTICOS DE MADRID O CATALUÑA EN 2017

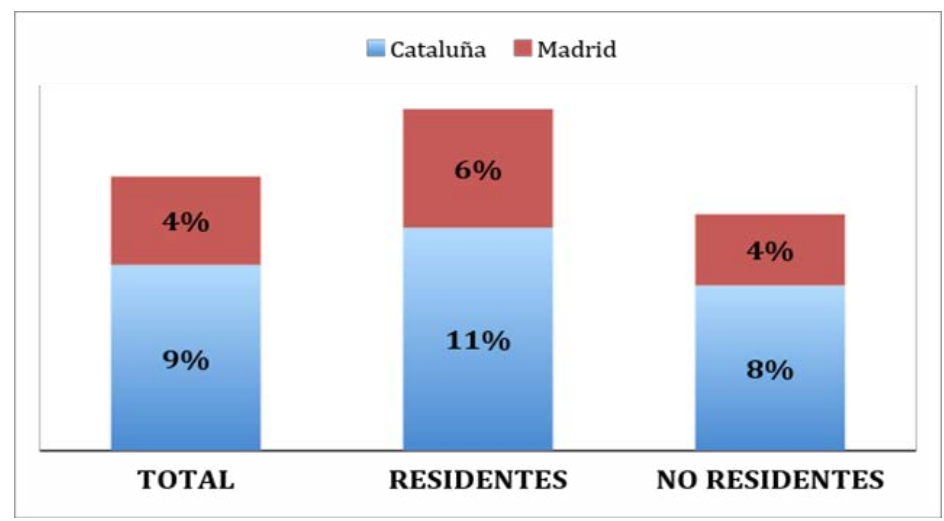

Fuente: Elaboración propia a partir la Encuesta de Ocupación Hotelera Española del INE, 2018. 
En cuanto al grado de ocupación medio de los apartamentos en 2017, tan solo la ciudad madrileña supera la media nacional, que es un 61,6\% frente al 70,4\% de Madrid, siendo en Cataluña el 50,5\% (según la Encuesta de Ocupación Hotelera del INE, 2017).

Este dato puede crear dudas, pero también puede anticipar la necesidad de información más elaborada sobre los apartamentos turísticos. Ya que es evidente como España es un país, donde la preferencia por la propiedad de la vivienda es una realidad extendida, por lo que las posibilidades de potenciar este mercado paralelo de alojamientos se multiplican (Moreno, Ramón y Such, 2016). Por este motivo, cabría tener en cuenta hasta qué punto la información pública disponible de los apartamentos turísticos, está reflejando la situación real de los mismos.

La restricción es que la estadística oficial estudia los “Apartamentos reglados o legales" pero no la oferta alegal o ilegal, en ciertos casos, de ahí la importancia de medir los datos de esta oferta mediante otras fuentes

\subsection{Análisis específico de la demanda y oferta alojativa reglada de Madrid}

Madrid, según el Índice de Ciudades Inteligentes de la International Data Corporation (2011), aparece dentro de las ciudades con los mejores resultados por la inteligencia de sus servicios de emergencia (se recogen datos de 2011 porque es el último estudio que selecciona datos de España).

La evolución de la mayoría de las series de la demanda y la oferta alojativa de Madrid ayuda a ver el impacto de la economía colaborativa y, particularmente, de la famosa plataforma "colaborativa" Airbnb que nació en 2008.

Por el lado de la demanda, dos series principales serán viajeros y pernoctaciones (ver figura 3). Aplicadas en este caso al sector hotelero, en el caso de Madrid, se presentan dos situaciones distintas, según procedencia: pues si se hace una valoración desde el punto de vista de los viajeros, hay más residentes que no residentes, que visitan la ciudad madrileña. Pero realizan un número mayor de pernoctaciones los no residentes, por lo que al fin y al cabo tanto los residentes como los no residentes tendrán una importancia significativa en este estudio.

Por el lado de la oferta, cabe destacar la situación de las plazas hoteleras (ver figura 4), por la situación crispada que se está desarrollando en los últimos años entre los hoteleros y la plataforma Airbnb. A pesar de la elevada representatividad actual de esta plataforma, se observa en la evolución del número de plazas hoteleras, que la propagación de estos apartamentos no ha tenido una repercusión tan elevada en la aparición o mantenimiento de establecimientos hoteleros, puesto que no hay un decrecimiento permanente en el tiempo desde la creación de la plataforma. Es más, se podría añadir que la serie presenta un crecimiento constante hasta el 2012, el peor año de la crisis en España, aunque en los últimos años ese crecimiento se haya detenido un poco; sin embargo en 2017 parece que vuelve a crecer. Este, será uno de los primeros matices que llevarán a cuestionar si realmente el sector hotelero se ha visto tan afectado frente a la aparición de dichas plataformas digitales. 


\section{Figura 3}

MADRID: VIAJEROS QUE SE ALOJAN EN HOTELES Y PERNOCTACIONES HOTELERAS SEGÚN PROCEDENCIA EN 2017²

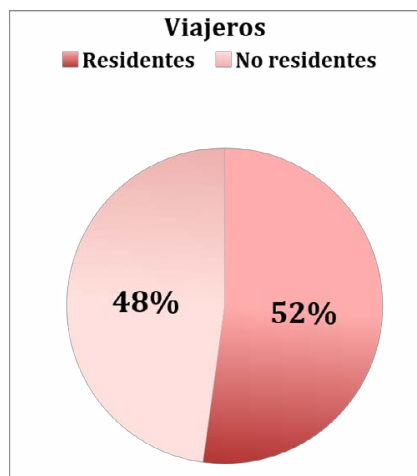

\author{
Pernoctaciones \\ Residentes No residentes
}

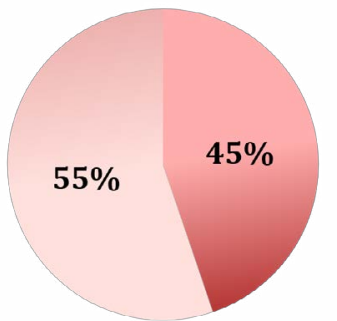

Fuente: Elaboración propia a partir de la Encuesta de ocupación hotelera del INE, 2018.

\section{Figura 4 \\ MADRID: EVOLUCIÓN NÚMERO DE PLAZAS HOTELERAS DESDE LA CREACIÓN DESDE 2001 (PROMEDIO ANUAL)}

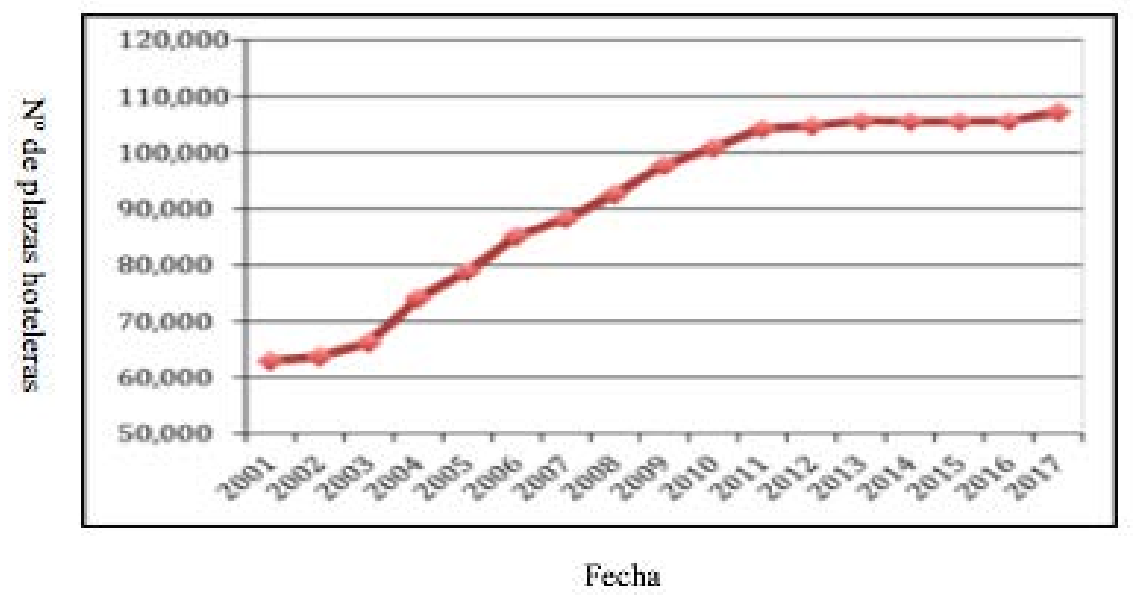

Fuente: Elaboración propia a partir de datos de la encuesta de ocupación hotelera del INE, 2018.

Después de ver la evolución del número de plazas hoteleras, se analiza la evolución del grado de ocupación de las mismas (ver figura 5). En este caso se puede observar

2 En la metodología de la Encuesta de ocupación hotelera y en la Encuesta de Ocupación en Apartamentos Turísticos del INE, se realiza una distinción en la procedencia del turista: Residentes en España (Residentes) y Residentes en el extranjero (No residentes). 
cómo se experimentó un rápido descenso de 2007 a 2009 y, a pesar de que hubo un repunte, la serie continuó decreciendo hasta finales del 2014. Por otra parte, se observa cómo, a partir de ese período el grado de ocupación de las plazas hoteleras crece y retoma un ritmo exponencial de crecimiento, aunque entre 2016 y 2017 haya una desaceleración del ritmo de incremento y no se experimente un aumento evidente. Por todo ello a pesar de que la proliferación de apartamentos no reglados en la capital pueda haber afectado al sector hotelero, este continúa manteniendo y mejorando su grado de ocupación en los últimos años.

\section{Figura 5 \\ MADRID: EVOLUCIÓN ANUAL DEL GRADO DE OCUPACIÓN DE PLAZAS HOTELERAS DESDE 2000. (PROMEDIO ANUAL)}

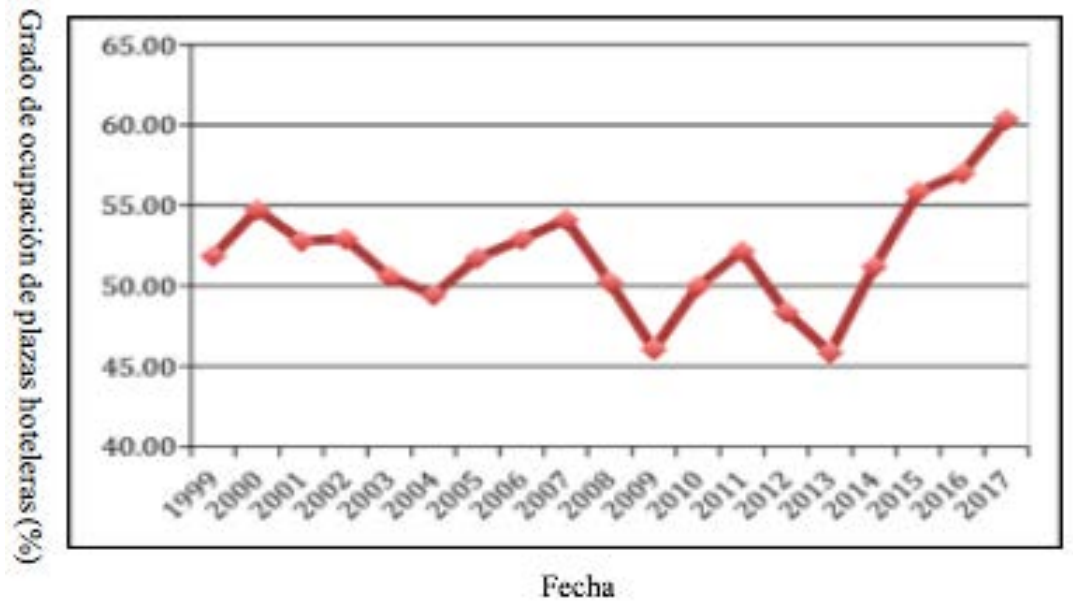

Fuente: Elaboración propia a partir de datos de la encuesta de ocupación hotelera del INE, 2018.

Desde la perspectiva de la demanda de los apartamentos en Madrid, se extrae que los turistas no residentes superan tanto en número de viajeros como en número de pernoctaciones a los residentes; aunque la diferencia porcentual entre ambos no es muy notable (ver figura 6) y, por tanto, ambos grupos son importantes para el estudio.

Por el lado de la oferta de los apartamentos turísticos, también se debe valorar la evolución de plazas (ver figura 7), ya que, si las cifras de esta serie fuesen totalmente esclarecedoras, se debería comprobar un aumento continuo, creciente y sostenido en el tiempo de los apartamentos turísticos desde 2008. La serie muestra un ritmo de crecimiento bastante acelerado del 2009 hasta 2010, pero a partir de ese punto experimenta un decrecimiento hasta aproximadamente mediados del 2013, período en el que España resurge de la crisis. Teniendo en cuenta que los apartamentos proliferaron precisamente motivados por la crisis, puede llevar a plantear si quizás las cifras recolectadas por el INE no son tan representativas de la situación real que experimentan los apartamentos, añadiendo que la cifra de estos en Madrid oscila entre los 6.000 y 11.000 apartamentos entre 2008-2017, 
una cifra que aparentemente no se adecua a la situación que está experimentando la capital frente a la "invasión apartamentística".

\section{Figura 6 \\ MADRID: VIAJEROS QUE SE ALOJAN EN APARTAMENTOS TURÍSTICOS Y PERNOCTACIONES DE APARTAMENTOS TURÍSTICOS SEGÚN PROCE- DENCIA EN $2017^{3}$}
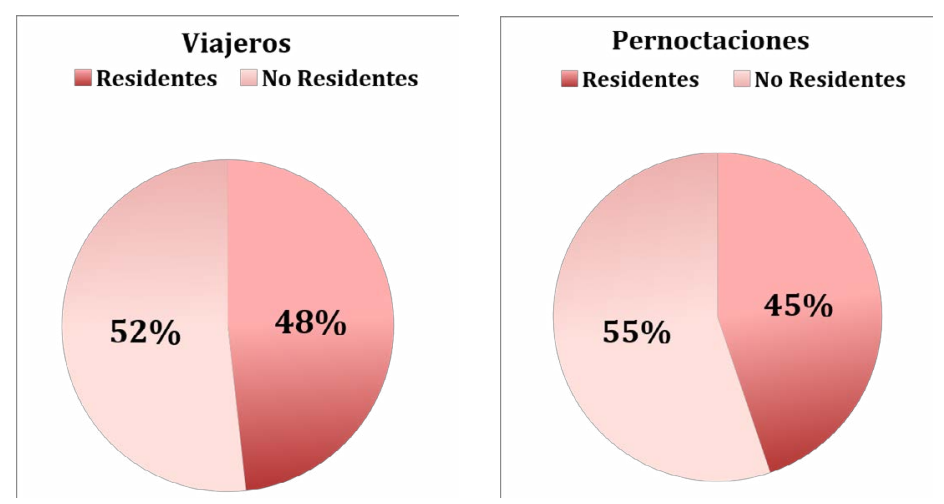

Fuente: Elaboración propia a partir de datos de la encuesta de ocupación en apartamentos turísticos del INE, 2018.

Una vez analizada la evolución de las plazas, también considerar, la evolución anual del grado de ocupación de los apartamentos turísticos. En Madrid, se observa que la caída más brusca de la serie se experimenta en 2007, con una recuperación que no se percibe hasta mediados del 2009. Aunque no tan brusca la serie sufre otro decrecimiento bastante notable en 2011 hasta mediados del 2014, que es el momento en el cual el grado de ocupación se recupera y comienza a ascender de nuevo, con un crecimiento continuo hasta 2016-2017, momento en el que parece que la serie pudiese comenzar a decrecer otra vez. Se presenta una situación positiva, pero bastante parecida a la de los hoteles, aunque en cierto grado menor a estos y de ningún modo se da un crecimiento progresivo en la serie a partir del surgimiento de Airbnb en 2008. Por todo ello, lo que reflejarían los grados de ocupación es que los hoteles estarían por delante de los apartamentos.

3 En la metodología de la Encuesta de ocupación hotelera y en la Encuesta de Ocupación en Apartamentos Turísticos del INE, se realiza una distinción en la procedencia del turista: Residentes en España (Residentes) y Residentes en el extranjero (No residentes). 


\section{Figura 7 \\ MADRID: EVOLUCIÓN NÚMERO DE PLAZAS DE APARTAMENTOS TURÍSTICOS DESDE 2001 (PROMEDIO MENSUAL)}

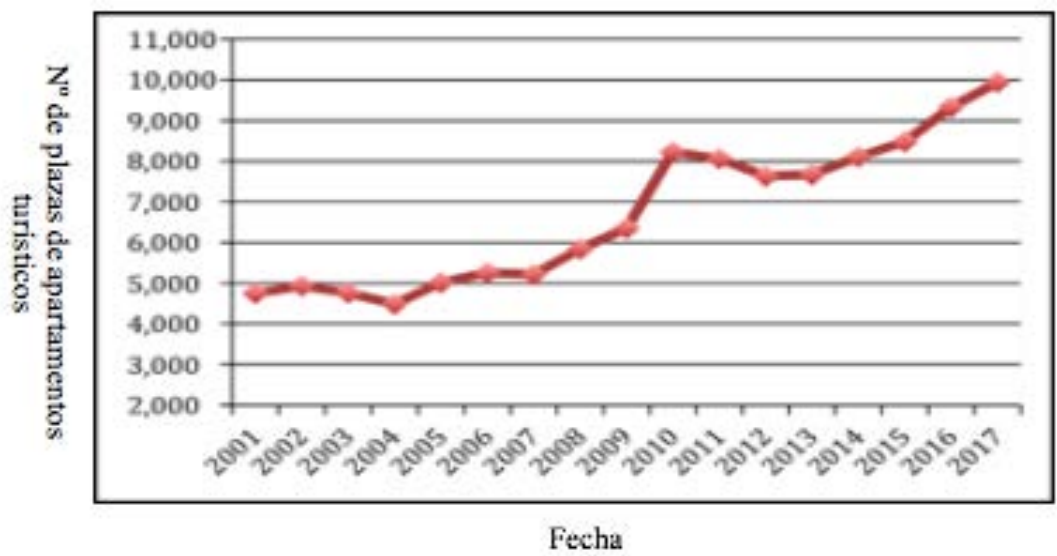

Fuente: Elaboración propia a partir de datos de la encuesta de ocupación en apartamentos turísticos del INE, 2018.

\subsection{Análisis específico de la demanda y oferta alojativa reglada de Barcelona}

En este apartado se analiza el caso de Barcelona, que como ya se dijo, según el Índice de Ciudades Inteligentes, aparece dentro de las ciudades con los mejores resultados por su eficiencia en movilidad. Por ello, se va a realizar seguidamente un análisis cuantitativo exhaustivo de la demanda y oferta alojativa de Barcelona, con el fin de para poder comprender mejor la situación de las mismas.

En el caso de Barcelona, se presentan, por el lado de la demanda, las mismas series principales: viajeros y pernoctaciones del sector hotelero. Se percibe una desigualdad más acentuada entre residentes y no residentes (ver figura 8) que en Madrid.

La Figura 8 muestra que los no residentes representan un porcentaje muy elevado (80\%) de los viajeros y de las pernoctaciones hoteleras de Barcelona.

Se analiza la evolución de las plazas hoteleras que, desde 2001 (ver figura 9), muestra un crecimiento constante. En este sentido, se ha de tener en cuenta que en Barcelona la presión contra los apartamentos turísticos es todavía mayor, por parte no solo del sector hotelero, sino también de los residentes.

La serie que recoge la Figura 9 muestra que los hoteles no se han visto tan afectados por el modelo de negocio paralelo de los apartamentos. 


\section{Figura 8 \\ BARCELONA: VIAJEROS QUE SE ALOJAN EN HOTELES Y PERNOCTACIONES HOTELERAS SEGÚN PROCEDENCIA EN 2017}

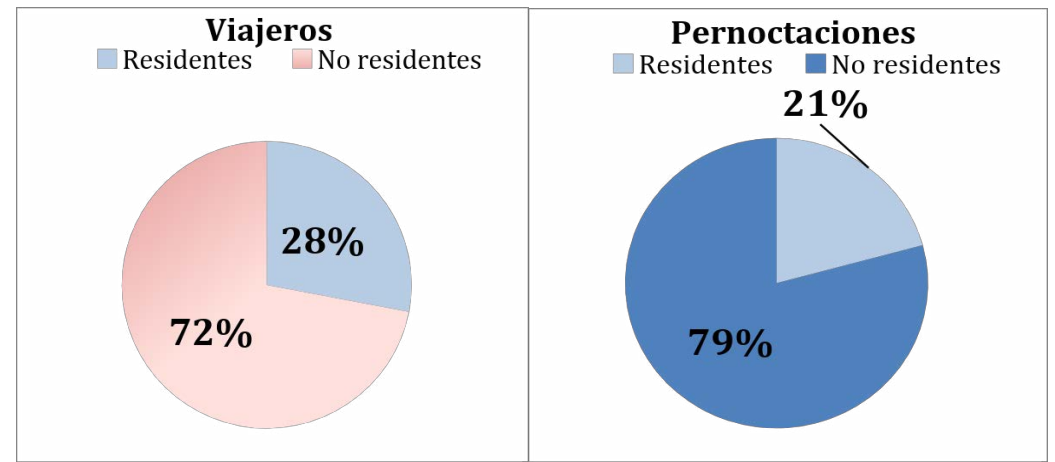

Fuente: Elaboración propia a partir de datos de la encuesta de ocupación hotelera del INE, 2018.

\section{Figura 9}

BARCELONA: EVOLUCIÓN NÚMERO DE PLAZAS HOTELERAS DESDE 2001 (PROMEDIO ANUAL)

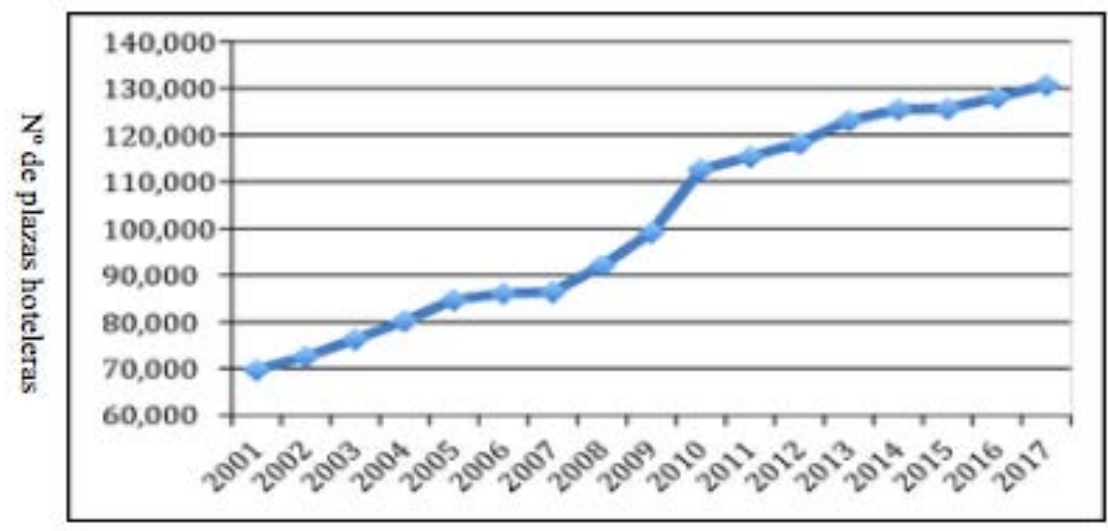

Fecha

Fuente: Elaboración propia a partir de datos de la encuesta de ocupación hotelera del INE, 2018.

En cuanto a la evolución anual del grado de ocupación por plazas hoteleras (ver figura 10), se puede observar como en Barcelona se experimenta una caída bastante acentuada en el periodo entre 2007 y 2009, y aunque posteriormente hay un repunte, se vuelve a experimentar una caída de la serie, aunque más leve, entre el 2011 y 2013 . Posteriormente, la serie experimenta un crecimiento notable, por lo que nos lleva a la misma conclusión que en el caso de Madrid: ¿Hasta qué punto los establecimientos hoteleros se han visto afectados por la proliferación de los apartamentos turísticos? 
Figura 10

BARCELONA: EVOLUCIÓN ANUAL DEL GRADO DE OCUPACIÓN DE PLAZAS HOTELERAS DESDE 1999. (PROMEDIO ANUAL)

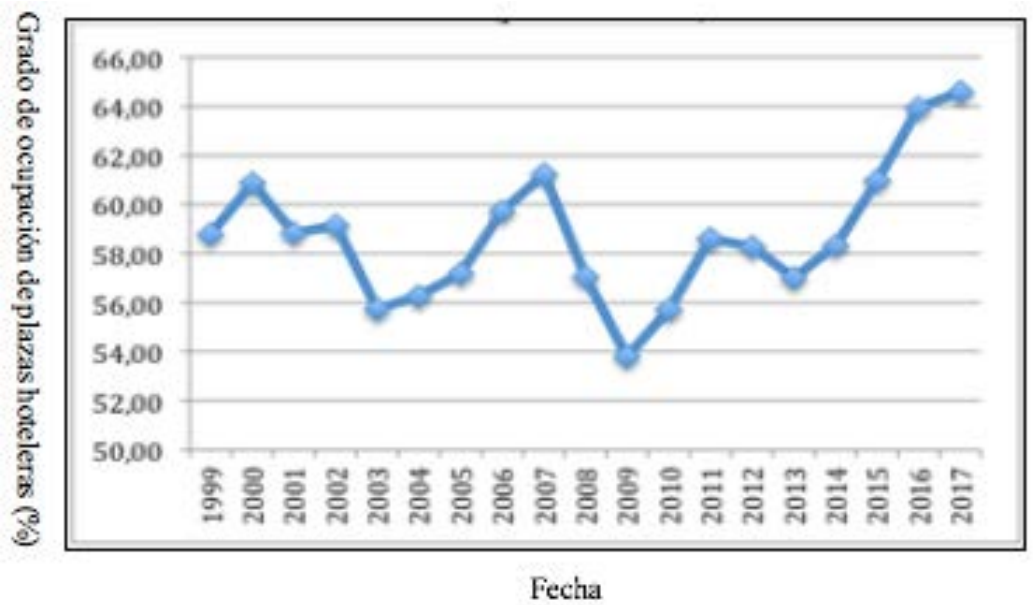

Fuente: Elaboración propia a partir de datos de la encuesta de ocupación hotelera del INE, 2018.

Desde la perspectiva de los apartamentos turísticos, por el lado de la demanda, si se analiza a la Comunidad de Cataluña en su conjunto (ver figura 11), los no residentes continúan destacando frente a los residentes, aunque en este caso la diferencia entre ambos no sea tan evidente.

Figura 11

\section{CATALUÑA: VIAJEROS QUE SE ALOJAN EN APARTAMENTOS TURÍSTICOS Y PERNOCTACIONES DE APARTAMENTOS TURÍSTICOS SEGÚN PROCEDENCIA EN 2017}
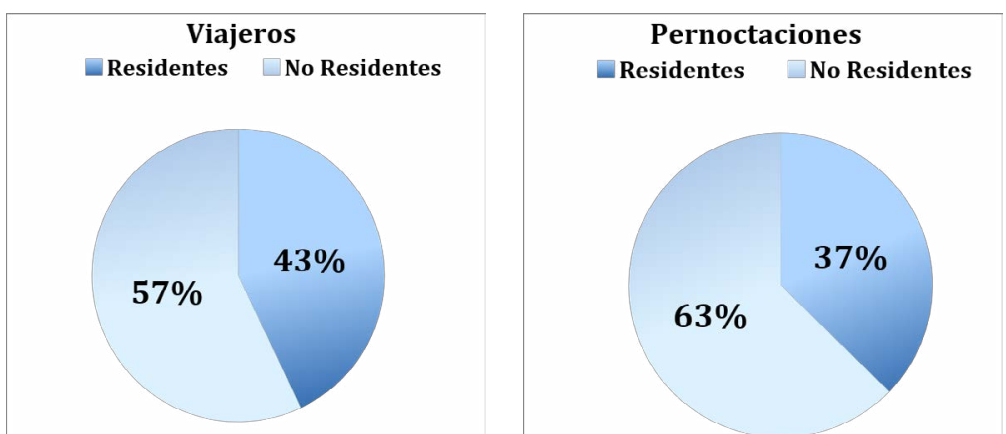

Fuente: Elaboración propia a partir de datos de la encuesta de ocupación en apartamentos turísticos del INE, 2018. 
La evolución del número de plazas de apartamentos turísticos (ver figura 12) refleja cómo, salvo entre 2002 y 2003 , no se han experimentado ritmos de crecimiento realmente notables en la serie, aunque también es cierto que no se registran descensos notables en ningún periodo.

Figura 12

CATALUÑA: EVOLUCIÓN NÚMERO DE PLAZAS DE APARTAMENTOS TURÍSTICOS DESDE 2001. (PROMEDIO MENSUAL)

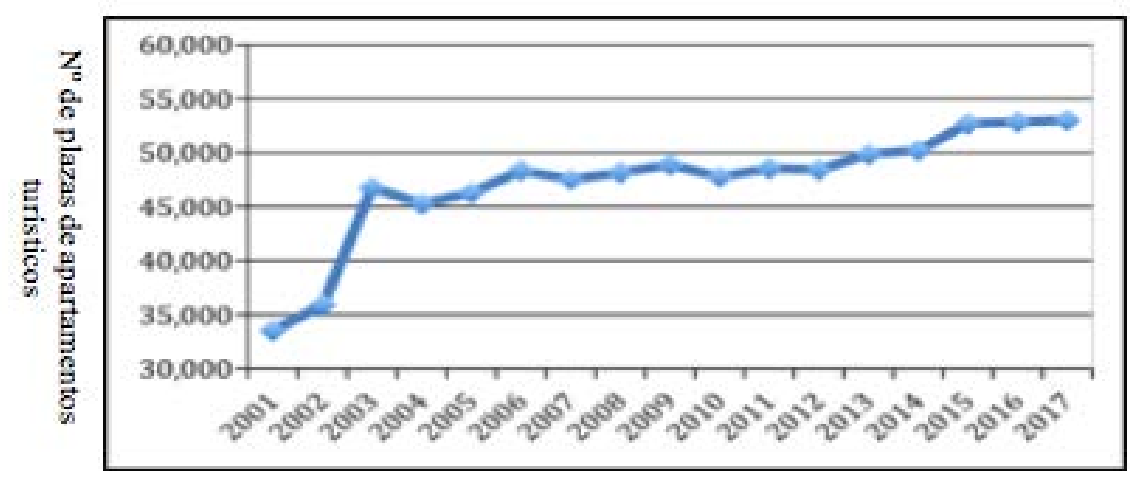

Fecha

Fuente: Elaboración propia a partir de datos de la encuesta de ocupación en apartamentos turísticos del INE, 2018.

\section{LA IRRUPCIÓN DE AIRBNB EN LA ESTRUCTURAALOJATIVA DE MADRID Y BARCELONA}

Al observar las limitaciones por parte del INE para cuantificar la realidad de los apartamentos turísticos en ambas ciudades, se decide realizar una aportación externa al INE. Se extraen datos de la base de datos del investigador Tom Slee (2018), investigador canadiense y especialista en tecnologías y temas sociales; con la finalidad de analizar de primera mano datos recientes de Airbnb, que permitan adentrarse en el panorama que están experimentando ambas ciudades con la aparición de dicha plataforma.

La elección de la plataforma Airbnb viene motivada porque dicha plataforma representa uno de los ejemplos más paradigmáticos de la conocida economía colaborativa, en la que cualquier persona puede alquilar su vivienda o habitación de su residencia privada como alojamiento turístico, con la particularidad de centrarse en el arrendamiento por cortos periodos de tiempo.

Por otra parte, Airbnb posee una capacidad expansiva tan importante que la ha convertido en pocos años en una de las grandes plataformas del sector turístico en su conjunto, consiguiendo transformar la demanda y la oferta alojativa del sector turístico, así como de influir en la vivienda residencial de muchos residentes. 
Se observa que, tanto Madrid como Barcelona, poseen distritos en la periferia que gozan de una capacidad territorial muy superior a los distritos céntricos y que, además, cuentan con un número reducido de apartamentos de Airbnb. La intervención de sus ayuntamientos se dirige a potenciar el turismo en algunas de estas áreas a través de acciones recogidas en el Plan Especial de Regulación del uso de Servicios Terciarios en la clase de Hospedaje $(\mathrm{PEH})^{4}$ para Madrid y en el Plan Especial Urbanístico para la Regulación de los Establecimientos de Alojamiento Turístico, Albergues de Juventud, Residencias Colectivas Docentes de Alojamiento Temporal y Viviendas de Uso Turístico (PEUAT) ${ }^{5}$ para Barcelona.

Ambas ciudades han optado por la forma de regulación más común: la limitación de los alojamientos Airbnb con ciertas restricciones (Nieuwland yVan Melik, 2018). Ambos planes proponen un modelo de regulación tradicional basado en la zonificación.

La diferencia radica en la delimitación de los ámbitos en las dos ciudades. En el caso de Madrid, dada la significativa concentración de viviendas de alquiler de uso turístico en el distrito centro madrileño y su decrecimiento con la distancia al centro de la ciudad, se propone un gradiente en la regulación dependiente de la proximidad al centro histórico (redistribución centrífuga del uso de hospedaje); el PEH propone una delimitación espacial en tres sectores en forma de anillos concéntricos. Estos anillos se establecen en función del estado de saturación de alojamientos turísticos a los que se ven afectados los diferentes barrios de la ciudad de Madrid.

En el caso de Barcelona se define su zonificación en: a) cuatro zonas específicas (ZE1, ZE2, ZE3, ZE4 (esta última con subzonas A, B y C)); b) una serie de Áreas de Tratamiento Específico por sus características morfológicas singulares; y c) varios Ejes Principales, coincidentes con vías estructurantes de la ciudad desde el punto de vista de la movilidad. El objetivo de esta delimitación espacial es el establecimiento de requisitos diferenciados para la implantación de alojamientos turísticos (Urquiaga, Riverola, Sanz y Sánchez, 2019).

Las dos ciudades imitan el modelo de otras capitales europeas con mayor dispersión en sus viviendas turísticas, como Berlín, Ámsterdam o París. Debe considerarse que la capacidad de autogestión turística del destino tiene que ser una parte primordial de un destino turístico inteligente, para evitar no sólo la masificación turística sino la gentrificación en determinados distritos.

\subsection{El impacto de Airbnb en Madrid: número de apartamentos, densidad de plazas turísticas por kilómetro cuadrado y precios (distribución por distritos)}

La distribución geográfica de ambas ciudades (Madrid y Barcelona) en distritos es completamente dispar, hecho que cabe tener en cuenta para comprender mejor el panorama en el que se encuentran inmersas. Madrid se compone de 21 distritos, frente a los 10 distritos en los que está estructurada Barcelona.

4 https://www.bocm.es/boletin/CM_Orden_BOCM/2019/04/23/BOCM-20190423-38.PDF

5 https://bop.diba.cat/temp/03_022017003806.pdf 
Airbnb tiene registrados en Madrid, 10.338 apartamentos completos en enero de 2018. Pero la distribución de los apartamentos por distritos es bastante dispar (ver figura 13), ya que únicamente el distrito centro, acoge al $62 \%$ de los apartamentos de la plataforma en Madrid. En el mapa, la zona centro es una parte ínfima de la provincia madrileña en su conjunto.

\section{Figura 13 \\ MADRID. DISTRIBUCIÓN DE LOS APARTAMENTOS COMPLETOS DE AIRBNB POR DISTRITOS}
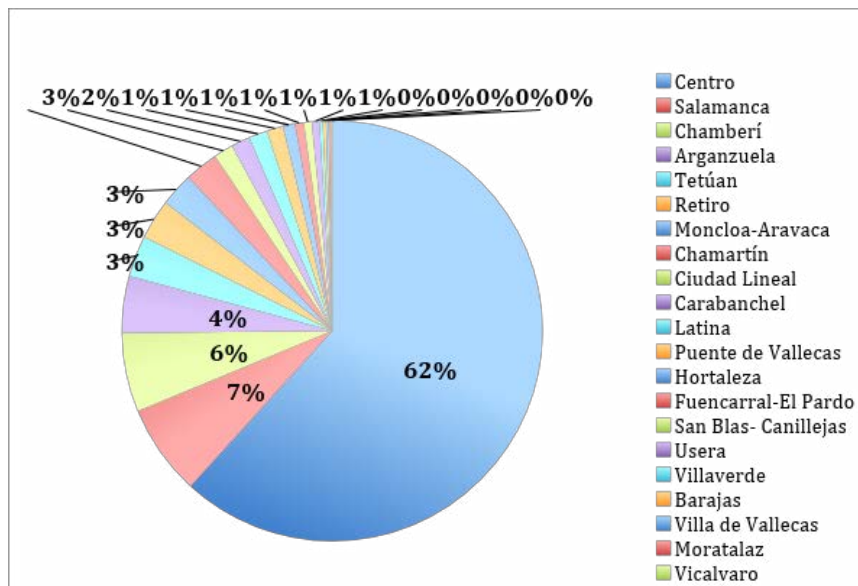

Fuente: Elaboración propia mediante los datos de Tom Slee del 2018.

El distrito centro acoge a más de la mitad de los apartamentos en un espacio geográfico muy limitado. Estos datos, son indicativos de la realidad que está experimentando la ciudad en términos de turistificación de las zonas céntricas. Posteriormente con un 7\%, un $6 \%$ y un $4 \%$, encontramos Salamanca, Chamberí y Arganzuela, respectivamente. Tras estos, encontramos cuatro distritos con un 3\% de los apartamentos cada uno: Tetuán, Retiro, Moncloa-Aravaca y Chamartín. Los restantes distritos contienen un $2 \%$ o menos de los apartamentos de Airbnb.

Al analizar la densidad de plazas turísticas de Madrid comercializadas en Airbnb por kilómetro cuadrado (ver figura 14), se detecta que las viviendas turísticas ofertadas en Airbnb se concentran abusivamente en el distrito Centro (con una densidad aproximada de 1219 plazas turísticas de Airbnb / km²).

A una distancia más que considerable, el distrito de Chamberí y el distrito de Salamanca (que poseen una densidad aproximada de 134 y 133 plazas turísticas de Airbnb / $\mathrm{km}^{2}$ ), por lo que la diferencia de densidad con el distrito centro es abismal, ya que este prácticamente decuplica lo que acogen estos otros distritos.

Tras los distritos Centro, Chamberí y Salamanca, con una diferencia bastante notable, se encuentran los distritos de Arganzuela, Tetuán y Retiro (con una densidad de 69, 61 
y 59 plazas turísticas de Airbnb / km², respectivamente). Posteriormente, los distritos de Chamartín, Ciudad Lineal y Carabanchel (con una densidad entre 30-11 plazas turísticas de Airbnb / km²).

Al analizar la disparidad entre distritos, se debe reflexionar sobre qué medidas son las idóneas para diluir la concentración en el distrito centro, ya que se comprueba que tanto las cifras absolutas como las relativas, nos indican una concentración alarmante en este distrito, requiriendo algún tipo de limitación.

\section{Figura 14 \\ DENSIDAD DE PLAZAS TURÍSTICAS DE MADRID COMERCIALIZADAS EN AIRBNB POR KILÓMETRO CUADRADO (2018)}

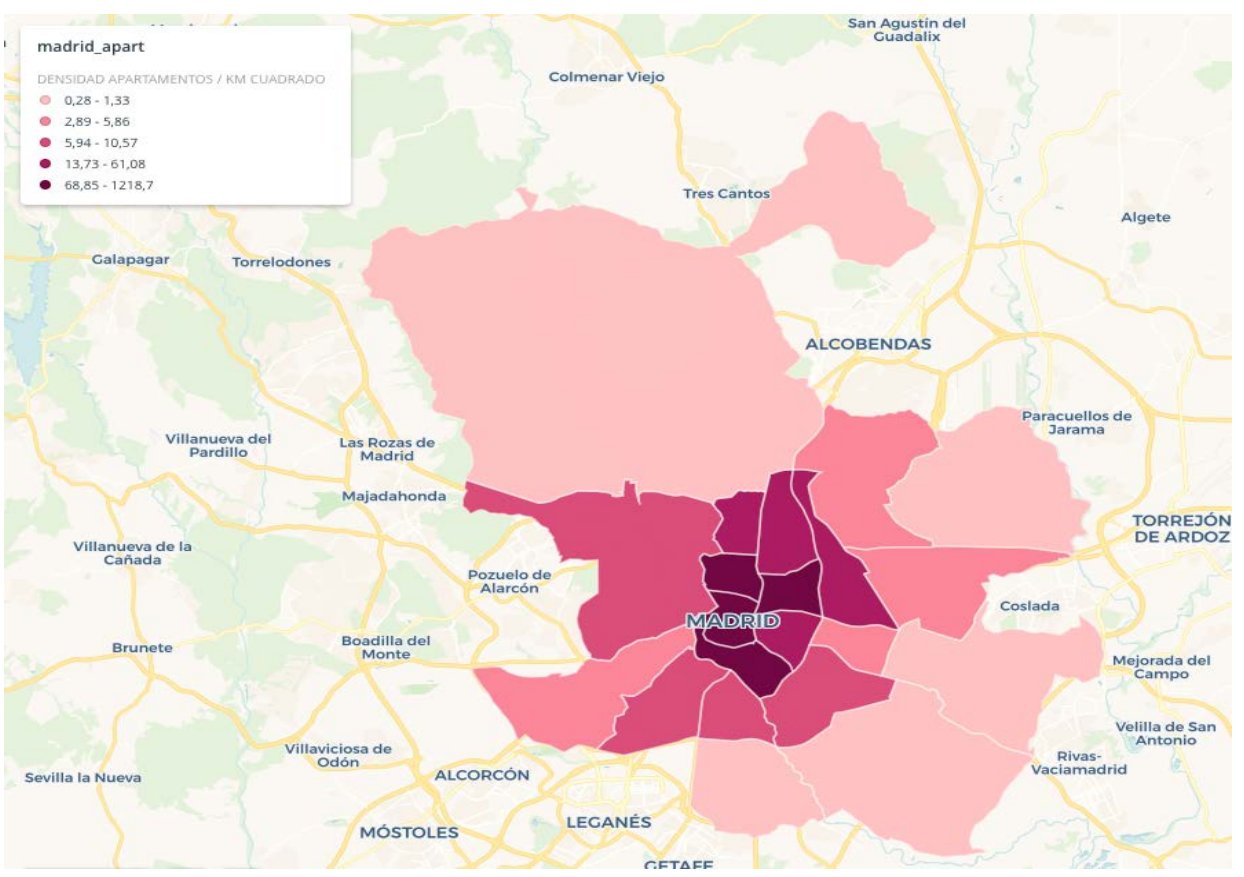

Fuente: Elaboración propia con la plataforma CARTO a partir de los datos de Tom Slee del 2018.

En cuanto a la distribución por distritos del precio medio por apartamento completo (ver figura 15) debe considerarse la siguiente evidencia: los distritos con mayor número de apartamentos, no se corresponden necesariamente con los distritos con mayor precio medio por apartamento. Es más, si se establece en el gráfico, una línea para determinar que distritos se quedan por debajo de la media por apartamento de la ciudad madrileña (94 euros) y que distritos están por encima; se examina que el distrito centro queda por debajo (93 euros), aunque muy próximo a la media de la ciudad por apartamento. En este caso los distritos que son iguales o superiores a la media son: Arganzuela, Chamberí, Hortaleza, Moncloa-Aravaca, Chamartín, Retiro y Salamanca; en orden ascendente. 
Así se puede concluir que no necesariamente existe una coincidencia entre las áreas con más oferta y demanda de apartamentos con las zonas con un mayor precio medio por apartamento. Por lo todo ello, la ciudad de Madrid debería tomar precauciones en la zona Centro y tratar de descongestionarla.

\subsection{El impacto de Airbnb en Barcelona: número de apartamentos, densidad de pla- zas turísticas por kilómetro cuadrado y precios (distribución por distritos).}

Frente a las limitaciones por parte del INE para cuantificar la realidad de los apartamentos turísticos en ambas ciudades, como ya se hizo en el caso de Madrid, se realiza una aportación externa, extrayendo datos de la base de datos del investigador Tom Slee (2018).

\section{Figura 15 \\ MADRID. DISTRIBUCIÓN POR DISTRITOS DEL PRECIO MEDIO POR APARTAMENTO COMPLETO}

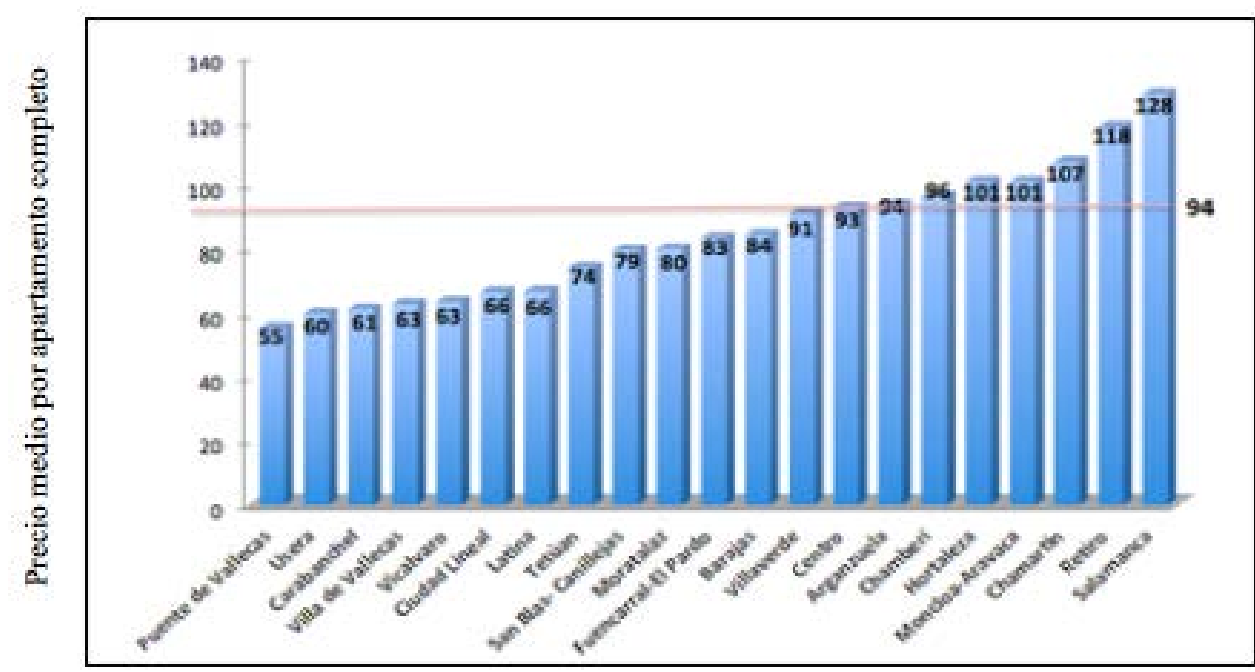

Distritos

Fuente: Elaboración propia a partir de base de datos de Tom Slee del 2018.

Barcelona posee registrados en abril de 2017, 8869 apartamentos completos en los 10 distritos de Barcelona.

Se observa que existen diferencias entre los diferentes distritos en referencia a la distribución de los apartamentos (ver figura 16). L'Eixample recoge el $36 \%$ de todos los apartamentos completos de Airbnb en Barcelona y, como se atisba en el mapa, no es el distrito más amplio. Posteriormente, se encuentra Ciutat Vella, que acoge un $20 \%$ de los apartamentos y considera uno de los distritos con mayor espacio geográfico. Pero, además, cabe recalcar que entre 1’Eixample y Ciutat Vella ya acogen un 56\% de todos los 
apartamentos completos de Airbnb en Barcelona, representando más de la mitad de todos los apartamentos de la ciudad condal. Ambos distritos se encuentran localizados muy próximos y acogen gran parte de la zona más céntrica de la ciudad.

\section{Figura 16 \\ BARCELONA. DISTRIBUCIÓN DE LOS APARTAMENTOS COMPLETOS DE AIRBNB POR DISTRITOS}

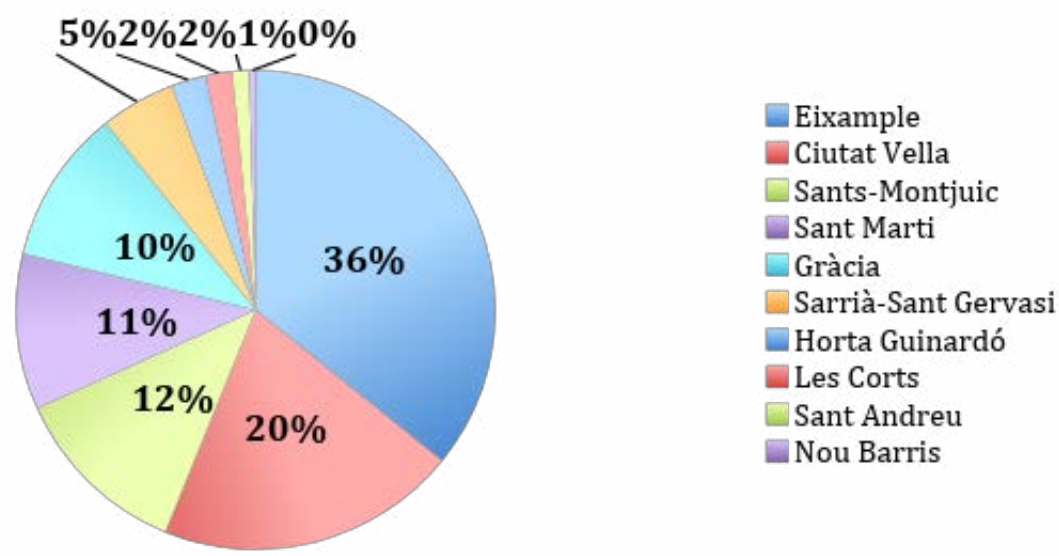

Fuente: Elaboración propia mediante los datos Tom Slee del 2017.

A continuación, hay tres distritos que individualmente representan, entre un $10 \%$ y un $12 \%$ de los apartamentos de Barcelona y son: Sants-Montjuic, Sant Martí y Gràcia, citados en orden de descendente de representatividad. Estos tres distritos se encuentran también muy próximos a los dos citados anteriormente, por lo que la zona en la que están concentrados los apartamentos turísticos de la plataforma Airbnb está claramente delimitada por la zona más céntrica de la ciudad.

Al profundizar en la mayor concentración de viviendas turísticas ofertadas en Airbnb (ver figura 17), se evidencia que, en el caso de Barcelona, las viviendas no se concentran en un único distrito, sino que son dos los distritos que concentran la mayor parte de la oferta de viviendas turísticas: L'Eixample y Ciutat Vella (con una densidad aproximada de 423 y 411 plazas turísticas de Airbnb/ $\mathrm{km}^{2}$ respectivamente).

Ambos distritos recogen una gran cantidad de apartamentos por $\mathrm{km}^{2}$, pero difieren notablemente frente a la cifra abusiva de densidad que posee el distrito centro madrileño. Posteriormente a estos dos distritos, con una amplia distancia, pero no tan extrema como en el caso de Madrid, están los distritos de Sant Martí y Gràcia, que cuentan una densidad aproximada de 155 y 115 plazas turísticas de Airbnb/ $\mathrm{km}^{2}$ respectivamente. Cabe destacar que cuatro distritos de la Ciudad Condal, cuentan con una densidad elevada de apartamentos por $\mathrm{km}^{2}$. Por otro lado, cabe destacar la proximidad geográfica entre ellos, lo que 
determina una gran concentración de apartamentos en distritos particularmente próximos, a lo que cabe prestar atención.

Aunque la disparidad en cuanto a las densidades entre distritos no sea tan evidente como en Madrid, esta sí concurre en la ciudad condal y debería analizarse, especialmente en aquellos distritos con una elevada densidad y cuya proximidad es evidente, considerando qué medidas serían las adecuadas para evitar la concentración en el centro histórico de Barcelona.

\section{Figura 17 \\ DENSIDAD DE PLAZAS TURÍSTICAS DE BARCELONA COMERCIALIZADAS EN AIRBNB POR KILÓMETRO CUADRADO (2017)}

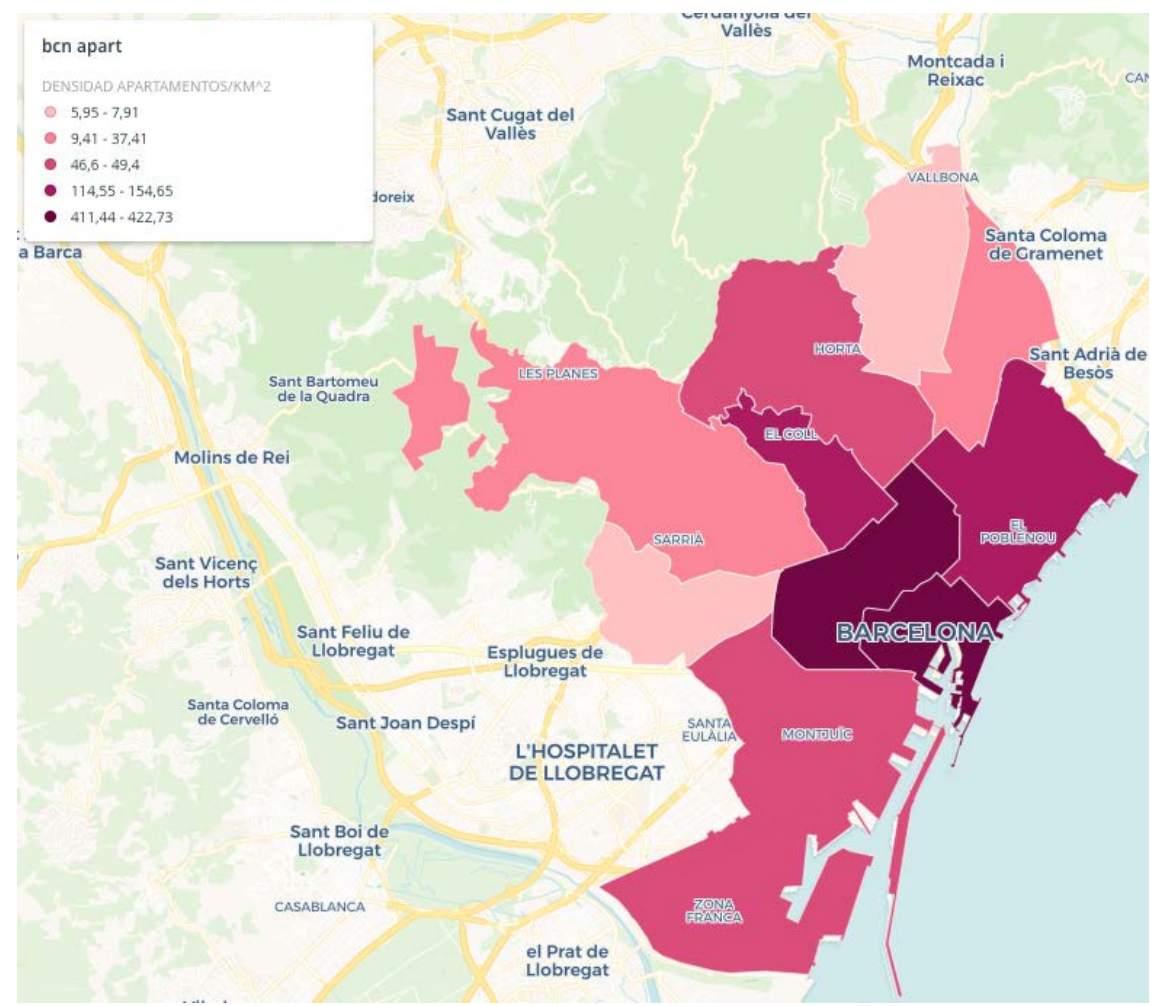

Fuente: Elaboración propia con la plataforma CARTO a partir de los datos de Tom Slee del 2017.

Si se realiza un análisis complementario sobre los precios por distritos (ver figura 18), se contempla que tan solo 4 distritos sobrepasan el precio medio de la ciudad para los apartamentos de Airbnb. Estos distritos son: les Corts, Sant Martí, Eixample y Sarrià-Sant Gervasi, ordenados de forma ascendente en cuanto a mayor precio medio por distrito. Cabe tener en cuenta que dos de los distritos que superan la media no pertenecen a los distritos que tienen una mayor concentración de apartamentos en la ciudad. Pero, 
a pesar de ello, destacan por poder permitirse tener un precio más alto por apartamento. Resaltamos, ante todo, el caso de Sarrià-Sant Gervasi, que goza de un precio medio de 175 euros, más de 20 euros de diferencia con el precio medio de L'Eixample, que es la zona céntrica con mayor concentración de apartamentos de toda Barcelona. Por lo que cabe prestar atención a que las zonas con mayor número de ingresos por apartamento no siempre son coincidentes con las zonas con mayor concentración de apartamentos; como ya se comentó anteriormente.

\section{Figura 18 \\ BARCELONA. DISTRIBUCIÓN POR AGRUPACIÓN DE BARRIOS DEL PRECIO MEDIO POR APARTAMENTO COMPLETO}

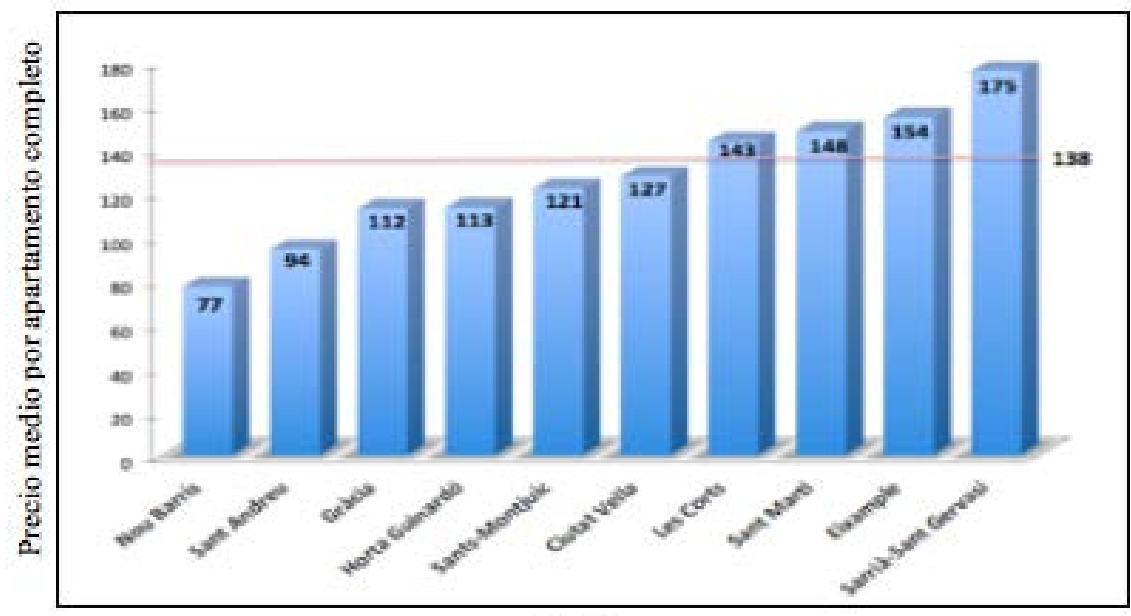

Distritos

Fuente: Elaboración propia a partir de base de datos de Tom Slee del 2017.

\subsection{Análisis de las diferencias de impacto de Airbnb en Madrid y Barcelona}

Una vez analizados los datos de la plataforma Airbnb, se perciben diferencias notables entre ambas ciudades que han de ser remarcadas.

Una de las diferencias más importantes es la propia distribución por distritos, que no solo se indica mediante un estudio de la distribución de los apartamentos por distritos, sino que una vez analizada la densidad de apartamentos por $\mathrm{km}^{2}$, se ve que el distrito centro de Madrid prácticamente triplica la cifra del distrito con mayor densidad de Barcelona. Así, como ya se indicó, resulta claramente alarmante la cifra recogida por el distrito centro madrileño.

Añadir a estas diferencias, que la concentración en el distrito centro de la ciudad madrileña es mucho más evidente que en la zona centro de Barcelona, ya que se encuentra más dispersa entre diversos distritos

Por otro lado, difiere mucho el precio medio de ambas ciudades. Mientras que en Barcelona es de 138 euros, en Madrid está en 94 euros. 
Para concluir se puede afirmar que, con todos los datos recogidos, ambos resultados distan notablemente de las aportaciones realizadas por el INE. Este hecho es un indicador de la necesidad de enriquecer la información que proporcionan las estadísticas oficiales sobre los apartamentos turísticos.

\section{CONCLUSIONES E IMPLICACIONES}

España es líder indiscutible en competitividad turística, pero mantener esa competitividad garantizando la conservación de los recursos del destino se convierte en una cuestión complicada a largo plazo.

El turismo surgió como una actividad con una capacidad de arrastre incalculable, pero gracias a su inclusión en el entorno digital, su capacidad de arrastre se hace aún más incontrolable. Esta nueva situación requiere analizar, detenidamente, las disrupciones en la demanda y la oferta turística.

Para realizar dicho análisis, se sugiere la presencia de indicadores de alerta temprana, que puedan tratar de detectar el límite real de la capacidad de carga de los destinos, teniendo en cuenta todas estas nuevas variables que se integran en el entorno y que en cierto modo lo determinan.

El origen de estos indicadores de alerta temprana puede partir de las propias estadísticas del INE, que cuentan con una amplia serie temporal, por lo que pueden ser idóneas para realizar previsiones de crecimiento. Pero, deben complementarse, como se indica en el presente estudio, con otros indicadores que contemplen la oferta no reglada. Así, esas previsiones de crecimiento podrán ser más precisas, a fin de garantizar la capacidad de los destinos a largo plazo.

La situación del sector turístico se está transformado de manera vertiginosa con la generalización masiva de la economía colaborativa y la aparición de un tipo de consumidor hiperconectado. La economía colaborativa, en el ámbito turístico, ofrece nuevas formas de viajar, de alojarse y de integrarse en la cultura local a un coste menor. Ante este nuevo escenario, resulta imprescindible abrir un espacio de debate orientado a reflexionar sobre la nueva realidad turística que se impone en el entorno social y económico. Se ha de trabajar en la cuantificación del impacto que está teniendo la economía colaborativa para crear nuevos indicadores que ayuden a analizar el impacto de la misma en el sector turístico. Por ello, se considera necesario poder medir los límites de dicha economía ya que, como muestra la presente investigación, se encuentran carencias en los indicadores actuales.

Así see detectan nuevas necesidades, que requieren de nuevos indicadores que incorporen no solo a la economía colaborativa y a la economía inteligente, sino a todas las variables que se ven afectadas con el desarrollo de las mismas.

En el transcurso del proyecto se dieron diversas limitaciones, destacando la ausencia de datos disponibles para cuantificar el impacto real, no solo de Airbnb o de los apartamentos no reglados, sino de los propios apartamentos turísticos reglados.

El proyecto se ha desarrollado con el análisis de dos ciudades, Madrid y Barcelona, debido a la importancia de ambas ciudades en el sector turístico español; y a que son ciudades que han sufrido mucha presión por parte de los residentes en contra de la turistificación. 
Por ello, se considera necesario poder cuantificar la situación real en la que se encuentran, ofreciendo una aportación diferenciada entre las mismas. Además, se reconoce la importancia de poder valorar la realidad turística de ambas metrópolis, de cara a poder regularla y mejorar la situación de los residentes y del destino.

El estudio desarrollado realiza una aportación complementaria desde dos tipos de alojamientos, los hoteles y los apartamentos turísticos, con el fin de conciliar de manera realista la situación actual de ambos. Además, se realiza una aportación externa al INE, extrayendo de la base de datos del investigador Tom Slee (2018): el número de alojamientos de Airbnb, su localización y su precio (tanto de Madrid como de Barcelona); con el fin de cuantificar la situación real de los apartamentos turísticos en ambas ciudades.

Se evidencia que, aunque ambas son grandes urbes, tienen necesidades y condiciones distintas, no solo por sectores de actividad, sino también por la distribución de la oferta y los flujos turísticos de sus distritos.

El estudio de la distribución geográfica por distritos es una de las aportaciones esenciales del presente estudio, ya que se evidencia que el distrito centro de Madrid prácticamente triplica la cifra del distrito con mayor densidad de Barcelona. Así, se observa que el distrito centro de la ciudad madrileña tiene una problemática mayor frente a la concentración de apartamentos turísticos. Además, se constata una distancia en los precios medios de dichos apartamentos entre ambas ciudades, que cabe denotar y analizar en futuras investigaciones, pues el precio medio por apartamento de Barcelona (138 euros) es notablemente superior al de Madrid (94 euros).

Se puede concluir, por tanto, que no hay una base más sólida que la información y el conocimiento, para hacer que un destino turístico pueda ser realmente inteligente y colaborativo y se dirija hacia la sostenibilidad turística, cultural y socioeconómica.

\section{BIBLIOGRAFÍA}

ALFONSO, R. (2016): «Economía colaborativa: un nuevo mercado para la economía social», CIRIEC-España, Revista de Economía Pública, Social y Cooperativa, ${ }^{\circ}$ 88, pp. 231-258.

ALONSO, M.M., CÁDIZ, M., FLECHA, M.D., GONZÁLEZ, L., RODRÍGUEZ-ANTÓN, J.M. y TALÓN, P. (2018): Turismo colaborativo. Documento 5, Comisión de Estudios de Turismo. AECA. Madrid

ALGAR, R. (2007): «Collaborative consumption», Leisure Report, pp. 16-17. Disponible en http://www.oxygen-consulting.co.uk/docs/collaborative-consumption.pdf>

BARDHI, F., y ECKHARDT, G.M. (2012): «Access-based consumption: The case of car sharing», Journal of Consumer Research, vol. 39 (4), pp. 881-898.

BELK, R. (2014): «You are what you can access: Sharing and collaborative consumption online», Journal of Business Research, vol. 67 (8), pp. 1595-1600.

BOTSMAN, R. y ROGERS, R. (2010): «What's Mine Is Yours: The Rise of Collaborative Consumption», Harper Business, pp. 15-16.

BUHALIS, D. y AMARANGGANA, A. (2013): «Smart tourism destinations», Information and Communication Technologies in Tourism, vol. 1, pp. 553-564. 
CAÑIGUERAL, A. (2014): «Vivir Mejor con Menos: Descubre las ventajas de la nueva economía colaborativa», Conecta, pp. 30-31.

CODAGNONE, C. y MARTENS, B. (2016): «Scoping the sharing economy: Origins, definitions, impact and regulatory issues», Institute for Prospective Technological Studies Digital Economy Working Paper, vol. 1.

DE LA ENCARNACIÓN, A.M. (2016): «El alojamiento colaborativo: Viviendas de uso turístico y plataformas virtuales», Revista de Estudios de la Administración Local y Autonómica, $\mathrm{n}^{\circ} 5$, pp. 30-55.

DOMÉNECH, G. (2015): «La regulación de la economía colaborativa. El caso Uber contra el taxi.», Revista Práctica de Derecho, vol. 175-176, pp. 61-104.

DUBOIS, E., SCHOR, J. y CARFAGNA, L. (2014). «Connected consumption: a sharing economy takes hold», Rotman Management, vol. 1, pp. 50-55.

FELSON, M. y SPAETH, J.L. (1978): «Community structure and collaborative consumption: A routine activity approach», American Behavioral Scientist, vol. 21 (4), pp. 614-624.

FERNÁNDEZ, A., LÓPEZ, J.M., MORENO, L., PERLES, J.F., RAMÓN, A.B y SUCH, M.J. (2017): «Innovación y destinos inteligentes: oportunidad para el knowhow turístico español.»Disponible en: https://rua.ua.es/dspace/bitstream/10045/68402/1/2017_Fernandez-Alcantud_etal_ICE.pdf.

GANSKY, L. (2010): The mesh: Why the future of business is sharing. Penguin.

GARCÍA, B. y SALVAJ, E. (2017): «Asociacionismo, redes y marketing en la transformación hacia el turismo experiencial. El caso del Barrio de las Letras, Madrid», Cuadernos de Turismo, $\mathrm{n}^{\circ}$ 40, pp. 315-338

HAMARI, J.; SJÖKLINT, M. y UKKONEN, A. (2016): «The sharing economy: Why people participate in collaborative consumption», Journal of the Association for Information Science and Technology, vol. 67, pp. 2.047-2.059.

KOO, C., SHIN, S., GRETZEL, U., CANNON HUNTER, W. y CHUNG, N. (2016): «Conceptualization of smart tourism destination competitiveness», Asia Pacific Journal of Information Systems, vol. 26 (4), pp. 561-576.

LEAL, M.P. y MEDINA, F.X. (2018). «Turismo y economía colaborativa: El caso de los recorridos gratuitos a pie en Barcelona», Cuadernos de Turismo, $\mathrm{n}^{\circ} 41$, pp. 323-341.

LÓPEZ DE ÁVILA, A. y GARCÍA, S. (2015): «Destinos turísticos inteligentes», Economía industrial, $\mathrm{n}^{\circ} 395$, pp. 61-69.

MORENO, L. RAMÓN, A. y SUCH, M.J. (2016): «Turismo colaborativo: ¿Está Airbnb transformando el sector del alojamiento?», Economistas, n ${ }^{\circ}$ 150, pp. 107-119.

MUÑOZ, A y SÁNCHEZ, S. (2013): «Destinos turísticos inteligentes», Harvard Deusto Business Review, vol. 224, pp. 58-67.

NIEUWLAND, S. y VAN MELIK, R. (2018): «Regulating Airbnb: how cities deal with perceived negative externalities of short-term rentals. », Current Issues in Tourism, 1-15. https://doi.org/10.1080/13683500.2018.1504899

OCU-UCM (2016): «Informe ejecutivo. ¿Colaboración o Negocio?», Revistas OCUCompra Maestrea, $\mathrm{n}^{\circ} 410$.

OPCIONES (2013): «Economías colaborativas»,Revista Opciones, no 44. Disponible en http://opcions.org/es/revista/44-economias-colaborativas. 
RIVERA, M. (2013): «El Turismo Experiencial Como Forma De Turismo Responsable E Intercultural», pp. 199-217. Jornadas sobre Investigación e Innovación para la Interculturalidad, Córdoba 2013. Disponible en https:/www.redalyc.org/ pdf/174/17449696009.pdf

RODRÍGUEZ-ANTÓN, J.M., ALONSO-ALMEIDA, M.M., RUBIO-ANDRADA, L. y PEDROCHE, M.S.C. (2016): «La economía colaborativa. Una aproximación al turismo colaborativo en España», Revista de Economía Pública, Social y Cooperativa, $\mathrm{n}^{\mathrm{o}} 88$, pp. 258-283.

SAINZ, M. (2015): «La ciudad en la economía de la experiencia: diseño, gestión y rol de los ciudadanos. Reflexiones y propuestas desde Bilbao.» Working paper presentado en International Conference on Regional Science. Disponible en http://www.reunionesdeestudiosregionales .org/Oviedo2013/htdocs/pdf/p658.pdf

SCHOLZ, T. (2016): Platform Cooperativism: Challenging the Corporate Sharing Economy, Rosa Luxemburg Stiftung.

SCHOR, J. (2015): The sharing economy: reports from stage one, unpublished paper, Boston College.

SCHOR, J. B., y FITZMAURICE, C.J. (2015): 26. «Collaborating and connecting: the emergence of the sharing economy», Handbook of research on sustainable consumption, 410.

TUSSYADIAH, I.P. y PESONEN, J. (2015): «Impacts of peer-to-peer accommodation use on travel patterns», Journal of Travel Research, vol. 55 (8), pp. 1.022-1.040.

URQUIAGA, A.A., RIVEROLA, I.L., SANZ, I.M., y SANCHEZ, J.R. (2019): “"No estamos tan mal como Barcelona": análisis de la proliferación y regulación de las viviendas de uso turístico en Madrid y Barcelona», Boletín de la Asociación de Geógrafos Españoles, 83, 7.

VAUGHAN, R. y HAWKSWORTH, J. (2014): The sharing economy: How will it disrupt your business. London, Price Waterhouse Coopers.

\section{WEBGRAFÍA}

COMISIÓN NACIONAL DE LOS MERCADOS Y LA COMPETENCIA (2016): Consulta pública sobre los nuevos modelos de prestación de servicios y la economía colaborativa. Disponible en https://www.cnmc.es/novedades/2016-03-11-la-cnmcsomete-consulta-publica-las-conclusiones-preliminares-sobre-los-nuevos

EUROPEAN CITIES MARKETING (2016): Organización sin ánimo de lucro para la mejora de la competitividad y los resultados de las principales ciudades de Europa. Plataforma de conocimientos de ocio y de marketing ciudades. Disponible en: http:// www.europeancitiesmarketing.com/

INTERNATIONAL DATA CORPORATION (2011): Análisis de las ciudades inteligentes en España. Madrid: IDC España. Disponible en https://www.aeiciberseguridad.es/ descargas/categoria6/8883484.pdf

INSTITUTO NACIONAL DE ESTADÍSTICA. (2018): Encuesta de ocupación hotelera, CCAA.1999-2017. Disponible en http://www.ine.es/dynt3/inebase/es/index.htm 
INSTITUTO NACIONAL DE ESTADÍSTICA. (2018): Índice de precios hoteleros, CCAA. 2002-2017. Disponible en http://www.ine.es/dynt3/inebase/es/index.htm

INSTITUTO NACIONAL DE ESTADÍSTICA. (2018): Indicadores de rentabilidad, CCAA. 2008-2017. Disponible en http://www.ine.es/dynt3/inebase/es/index.htm

INSTITUTO NACIONAL DE ESTADÍSTICA. (2018): Encuesta de ocupación en apartamentos turísticos, CCAA. 2000-2017. Disponible en http://www.ine.es/dynt3/inebase/ index.htm

INSTITUTO NACIONAL DE ESTADÍSTICA. (2018): Índice de precios de apartamentos turísticos, Nacional. 2003-2017. Disponible en http://www.ine.es/dynt3/inebase/es/ index.htm

MASTERCARD (2017): MasterCard Global Destination Cities Index. Disponible en https://newsroom.mastercard.com/wp-content/uploads/2017/10/Mastercard-Destination-Cities-Index-Deck.pdf

OUISHARE. (2016): Definición de economía colaborativa. Connecting the collaborative economy. Disponible en http://ouishare. net/es/

SLEE, T. (2018): Airbnb Data Collection: Get the data. Disponible en http://tomslee.net/ airbnb-data-collection-get-the-data 